\title{
CFRP flexural and shear strengthening technique for RC beams: experimental and numerical research
}

\author{
Joaquim A. O. Barros*, Inês G. Costa, A. Ventura-Gouveia \\ ISISE, Department of Civil Engineering, University of Minho, 4800-058, Guimarães, Portugal
}

\begin{abstract}
Near Surface Mounted (NSM) technique has proved to be a very effective technique for the flexural strengthening of RC beams. Due to the relatively small thickness of the concrete cover that several beams present, cutting the bottom arm of steel stirrups for the installation of NSM laminates might be a possible strategy, whose implications on the beam's load carrying capacity need to be assessed. When still stirrups are cut, however, the shear resistance can be a concern. This also happens when a strengthening intervention is carried out to increase the flexural resistance of a beam, since in certain cases it is also necessary to increase the shear resistance in order to avoid the occurrence of brittle shear failure. The present work assesses the effectiveness of a technique that aims to increase both the flexural and shear resistance of RC beams that have the bottom arm of the steel stirrups cut for the application of NSM laminates. This assessment is performed by experimental and numerical research. The main results of the experimental program are presented and analyzed, and the innovative aspects of a constitutive model implemented in a computer program are described, being their virtues and deficiencies discussed.
\end{abstract}

Keywords: CFRP; NSM; flexural strengthening; shear strengthening; FEM; material nonlinear analysis.

\footnotetext{
* Corresponding Author. Tel: +351 510 210; Fax: +351 253510217.

E-mail address: barros@civil.uminho.pt (Joaquim A. O. Barros).
} 


\section{Introduction}

The efficiency of the Near Surface Mounted (NSM) technique for the flexural strengthening of reinforced concrete (RC) beams [1-5] and slabs [6,7] has already been assessed. This technique consists of installing Carbon Fibre Reinforced Polymer (CFRP) laminates into thin slits open onto the concrete cover of the RC elements to strengthen. The CFRP laminates are bonded to the surrounding concrete with an epoxy adhesive. Available experimental [8] and analytical research [9] shows that the deeper the laminate is installed into the slip the higher is the ultimate strain that can be applied to the laminate, due to the confinement provided by the concrete surrounding the laminate. However, in general, the depth of the slit is limited to the thickness of the concrete that covers both the horizontal arm of the steel stirrups and the longitudinal steel bars, otherwise these arms have to be cut. Preliminary research revealed that cutting the bottom arm of the steel stirrups of NSM flexurally strengthened RC beams does not affect the beam's load carrying capacity $[10,11]$. However, this observation was obtained in an exploratory research, and the influence of relevant parameters like the dimensions of the beam, area and diameter of the longitudinal steel bars, and the percentage and spacing of existing steel stirrups was not treated. Therefore, one of the main motivations of the present work is to increase the knowledge related to the possibility of cutting the bottom arm of the existing steel stirrups for a deeper installation of NSM laminates.

Available research [11-13] reveals that the maximum ultimate strain that can be applied to the NSM laminates decreases with the increase of the equivalent flexural reinforcement ratio, $\rho_{l, e q}=A_{s} /\left(b d_{s}\right)+\left(A_{f} E_{f} / E_{s}\right) /\left(b d_{f}\right)$, being $b$ the beam width, $d_{s}$ and $d_{f}$ the effective depth of the longitudinal steel bars and NSM laminates, $E_{s}$ and $E_{f}$ the Young's Modulus of the longitudinal tensile steel bars and NSM laminates, $A_{s}$ and $A_{f}$ the cross sectional area of the longitudinal steel bars and laminates. The majority of the experimental programs deals with beams and slabs with $\rho_{l, e q}<0.4 \%[11]$. Since a higher efficiency is expected when using CFRP laminates installed deeper into the slit, in the present experimental program a $\rho_{l, e q}$ of about $0.5 \%$ is adopted for the strengthened beams of the tested series.

The NSM flexural strengthening effectiveness can be compromised if shear failure and/or detachment of the concrete cover that includes the NSM laminates (also designated by rip-off failure mode, Fig. 1a) occur prematurely. The tendency for the occurrence of the rip-off failure mode increases with the number of existing tensile steel bars, since due to the higher percentage of voids just below these bars a concrete "weak plane" exists at this level (Fig. 1b). Due to the eccentricity of the load in the laminates in relation 
to this concrete "weak plane", $t$, a local bending moment is actuating that introduces a gradient of tensile stresses in the concrete at the level of this plane, which magnitude increases with the load applied to the beam. In an attempt to avoid these types of failure modes, the effectiveness of an hybrid strengthening technique is investigated in the present work, being this technique composed of NSM CFRP laminates for the flexural strengthening, and Externally Bonded Reinforcement (EBR, [14]) wet layup CFRP strips of sheet for the shear strengthening. Amongst the EBR shear strengthening configurations, the full wrapping is the most effective $[15,16]$. However, to allow that the wet layup strips fully wrap the beam this technique requires the execution of apertures in the slab connected to the beam to be strengthened, which besides the extra costs of this procedure, is not allowed in certain cases. Therefore, in the present research, the $U$ shear strengthening configuration is adopted, placing the strips in-between the existing steel stirrups.

A full and comprehensive assessment of the influence of cutting the horizontal arm of existing steel stirrups for the installation of NSM laminates requires the execution of an experimental program composed of series of beams of distinct and independent parameters that affect significantly the behaviour of these beams. This requires a considerable investment in human and material resources, as well as a long research period of time. Since sophisticated FEM-based computer programs are available nowadays, their use can be a sustainable and a proper approach to obtain relevant information, if the values of the parameters of an appropriate constitutive model are calibrated using existing experimental data. This approach is followed in the present work. Therefore, using the FEMIX computer program [17], a new approach to model the crack shear propagation is implemented into the already existing multidirectional fixed smeared crack constitutive model [18], in order to accurately simulate the deformational behaviour of the shear and flexural/shear failed strengthened beams, as well as their crack patterns and failure modes. In fact, good predictions of the behaviour of beams presenting a ductile flexural failure mode can be obtained with available commercial FEM-based computer programs. However, accurate simulation of beams failing in shear or in flexural/shear is still a challenge in the computational mechanical domain. A flexural/shear failure mode means a beam that fails by the formation of a shear crack, after the longitudinal steel bars have already yielded.

In the present work, a total crack shear stress-shear strain approach is implemented to simulate the degradation of the shear stress transfer with the crack opening evolution. Using the results obtained in the tested beams, the predictive performance of this approach is compared to an already implemented model 
based on the incremental crack shear stress-shear strain approach [18]. The numerical simulations proved the better ability of the total approach to predict the full behaviour of the tested beams.

\section{Experimental program}

\subsection{Series of beams, material properties and monitoring system}

The experimental program is composed of three series of beams of distinct cross section depth, each one of four beams (see Table 1). For the generic $i^{\text {th }}$ series, the beams have the following designation:

- VRi - reinforced concrete reference beam;

- VEi - equal to VRi beam, but with the bottom arm of the steel stirrups cut;

- VLi - equal to VEi, and flexurally strengthened with NSM CFRP laminates;

- VLMi - equal to VLi beam, and shear strengthened with EBR strips of wet layup CFRP sheets of U configuration.

All beams have a cross section width $(b)$ of $0.2 \mathrm{~m}$ in order to assure the same anchorage length to the cut bottom arm of the steel stirrups (Fig. 2 and Table 1). The reinforcement ratio of the bottom longitudinal steel bars, $\rho_{s l}$, is almost equal in the three series, $0.37 \%$. A relatively high percentage of steel stirrups is applied in $L_{2}$ span ( $\phi 6 @ 95 \mathrm{~mm}, \phi 6 @ 130 \mathrm{~mm}$, and $\phi 6 @ 140 \mathrm{~mm}$ in series 1, 2 and 3, respectively) to avoid shear failure in this zone of the beams (Figs. 2 to 4). The spacing between steel stirrups in $L_{l}$ is the double of the spacing in $L_{2}$.

The percentage of NSM CFRP laminates applied in the VL and VLM beams of the series was designed in order to have the potential to double the load carrying capacity of the corresponding VR reference beam. However, this strengthening capacity can not be fully mobilized in beams without shear strengthening systems, since the VL beams were designed to have a shear resistance lower than the flexural capacity that NSM CFRP laminates can provide. This situation occurs frequently in real applications, where the existing shear resisting system can not support the extra-load predicted by the flexural strengthening strategy. As already mentioned, the second justification for the use of EBR-U shear strips is supported on the purpose of avoiding the occurrence of the rip-off type of failure mode. The aforementioned reasons justify the presence of VLM beams in the tested series, with a hybrid strengthening configuration in an attempt to avoid shear and rip-off failure modes. In fact, adopting a EBR U shear strengthening configuration of wet layup CFRP strips the beam's shear resistance increases and an extra resistance to the formation of the rip-off failure mode is applied. 
Two CFRP laminates of $1.4 \mathrm{~mm} \times 20 \mathrm{~mm}$ cross sectional area per beam $\left(A_{f}\right.$, Fig. 3$)$ are applied for the flexural strengthening. Since the fib bulletin 14 [19] does not present specific recommendations for the design of NSM flexural strengthening systems, the ACI 440 [14] recommendations were followed. However, for the design of the EBR shear strengthening configurations the fib guidelines [19] were adopted, and three strips of one layer of wet layup CFRP sheet of $50 \mathrm{~mm}$ width $\left(w_{f}\right)$ were determined and placed according to the scheme represented in Fig. 2.

Tables 2 and 3 present the values obtained in experimental tests with steel and CFRP specimens, respectively. The meaning of the symbols in these tables is indicated in the Notation Section. At 28 days the concrete presented an average compressive strength of $31.1 \mathrm{MPa}$ and a Young's Modulus of $28.9 \mathrm{GPa}$.

All the beams are monitored with one strain-gauge $(\mathrm{SG})$ installed on one longitudinal steel bar $\left(S G_{S L}\right)$, two SG applied on one steel stirrup $\left(S G_{S V}\right)$, one SG installed on each NSM laminate $\left(S G_{C L}\right)$ and three SG applied on the intermediate EBR strip of sheet $\left(S G_{C V}\right)$ (Figs. 4 and 5). The deflection of the beam at the loaded section is measured from an LVDT supported on an aluminium bar fixed at the alignments of the supports of the beam, in order to avoid extraneous readings, like beam support settlements and deformability of the test reaction frame (Fig. 2).

\subsection{Experimental results}

\subsubsection{Series 1 beams}

The behaviour of VR1 and VE1 was almost the same, either in terms of load carrying capacity as in crack pattern (Fig. 6). Both beams failed in bending, with the steel yield initiation at about $2.5 \mathrm{~mm}$ beam deflection, for a load of $58 \mathrm{kN}$.

In spite of having supported a load level significantly higher than its VR1 reference beam, the potential duplication of the load carrying capacity that NSM strips applied in VL1 beam could provide has not occurred due to the occurrence of a shear failure mode in VL1 beam, as expected. However, it is quite notable that, at the moment of the shear failure, the longitudinal steel bars were already yielded in all the beams of Series 1 (Fig. 7). In fact, the longitudinal steel bars started yielding at a beam deflection of 3.3 $\mathrm{mm}$, for a load of $79 \mathrm{kN}$ when the maximum strain in the CFRP strips was $3.2 \%$.

When compared to the VR1 and VE1, VL1 and VLM1 beams presented a higher stiffness after crack initiation. However, the behaviour of VLM1 beam shows that the applied shear strengthening system had marginal contribute for the beam's stiffness. 
Due to a premature debond of the bond transfer length of the shear strips crossed by the shear failure crack, VLM1 beam has also failed in shear, which was not expected. The longitudinal steel bars of VLM1 beam started yielding at a beam deflection of $3.2 \mathrm{~mm}$, for a load of $79 \mathrm{kN}$, when the maximum strain in the CFRP strips was 3.2\%o.

Fig. 7 and the results included in Table 4 show that cutting the bottom arm of the steel stirrups had no influence on the load carrying capacity of the beams of Series 1 , and that two NSM strips $\left(\rho_{f}=0.12 \%\right)$ provided an increment of about $40 \%$ in terms of beam load carrying capacity. In $2^{\text {nd }}, 3^{\text {rd }}$ and $4^{\text {th }}$ columns of Table 4 are indicated the age of the beams (in days) when the beams were tested, the NSM CFRP strips were applied and the strips of wet layup sheet were bonded, respectively.

In spite of VLM1 has failed in shear, Table 4 shows that the shear strengthening configuration adopted in this beam allowed an increase of about $80 \%$ in terms of beam load carrying capacity. Therefore, if shear failure had not occurred, it would be expectable that the NSM flexural system had doubled the load carrying capacity of the VR1 beam.

Fig. 8 compares the evolution of the strains in the NSM strips (average of the two monitored laminates) and in the longitudinal steel bars for the VL1 and VLM1 beams. It can be concluded that, up to the yielding of the longitudinal bars the variation of the strains in steel bars and CFRP strips was similar, revealing a perfect bond conditions between these strips and surrounding concrete. It is also visible that the shear strengthening system allowed the mobilization of a maximum strain of $10.0 \%$ in the NSM strips, which is $56 \%$ of the ultimate strain obtained experimentally in this material (Table 4), while in VL1 beam the occurrence of the shear failure mode limited the maximum strain in the NSM strips to $6.4 \%$.

The variation of the strains in the intermediate strip of CFRP sheet of VLM1 beam is shown in Fig. 9. At about $70 \mathrm{kN}$, this strip was crossed by the shear failure crack, leading to an abrupt and similar increment of strains in $S G_{C V 2}$ e $S G_{C V 3}$, while the strain variation in $S G_{C V 1}$ was very small, in consequence of being quite far from the shear crack plane and also due to a premature debonding at the free extremity of this strip. It is quite significant the $7.53 \%$ maximum strain at $S G_{C V 3}$, which is a little lower than the average value adopted in the design of the CFRP shear strengthening systems $\left(\varepsilon_{f, e}=8.5 \%\right.$, according to fib bulletin 14 [19]). 


\subsubsection{Series 2 beams}

As in Series 1, the behaviour of VR2 and VE2 beams of Series 2 was similar, showing that cutting the bottom arm of the stirrups did not influence the load carrying capacity of the tested beams. In similitude to what occurred in Series 1, VL2 beam of Series 2 also failed in shear. However, the inclination of the shear failure crack of VL2 beam was lower than the inclination occurred in VL1 beam. Furthermore, the shear failure crack of the VL1 beam has an almost constant inclination, while in the VL2 beam the inclination of the shear failure crack changed significantly along its development (Fig. 10a and 10b).

In the test of VLM2 beam, along the $L_{2}$ span (Fig. 2), the strips together with surrounding concrete were detached (Fig. 10c), which indicates that the shear strengthening system was very effective in terms of avoiding the occurrence of shear failure in the $L_{l}$ beam's span. This means that the total resisting bond length of the strips of sheet provided enough resistance in order to avoid the degeneration of the existing shear cracks into a shear failure crack.

Fig. 11 shows that in the bottom tensile face along the $L_{2}$ of VLM2 beam's span, a fish spine crack pattern was formed, in consequence of the stress transfer between strips and surrounding concrete $[1,6]$. In general, this crack pattern occurs when high stress levels are installed in the strips, which is an indicator of the high performance of the used adhesive in terms of strip-concrete bond behaviour. In fact, the maximum strain measured in the CFRP strips in VLM2 beam was 12.3\% (Table 4).

The relationship between the applied load and the deflection at the loaded beam section is represented in Fig. 12 for the four beams of Series 2. Table 4 includes the most significant results obtained in the tests of this series, where it is visible that the increment in terms of beam's load carrying capacity provided by the strengthening of two laminates $\left(\rho_{f}=0.090 \%\right)$ was $55 \%$, while combining the flexural and shear strengthening systems (VLM2) assured an increment of about 77\%. It is also observed that the loss of load carrying capacity due to the cut of the bottom arm of the stirrups was again very small.

Similar to what happened in the beams of Series 1, when the beams of series 2 failed, their longitudinal steel bars had already yielded. Furthermore, when shear failure crack formed in VL2 beam the longitudinal steel bars had already yielded (Fig. 12).

In terms of strain fields in steel longitudinal bars and NSM CFRP strips, they were similar to those measured in the homologous beams of Series 1 .

On the other hand, the strain field registered by the strain gauges installed on the strip of sheet of VLM2 beam (Fig. 13) was distinct of the one recorded in VLM1 (Fig. 9). Since in VLM2 beam a shear failure crack was not formed in the $L_{l}$ beam span where EBR strips of sheet were applied, the maximum strains 
registered in the monitored strip were lower than the corresponding ones measured in the strip of sheet of VLM1 beam.

\subsubsection{Series 3 beams}

Like in VRi and VEi beams of the Series 1 and 2, the VR3 and VE3 beams of Series 3 also failed in bending. However, while in the Series 1 and 2 the decrease of load carrying capacity due to the cutting of the bottom arm of the steel stirrups was marginal, in the VE3 beam the decrease was higher, around $10 \%$. This distinct behaviour may, however, not be totally related to the cutting of the steel stirrups, since a small inaccuracy in the positioning of the tension longitudinal steel bars, or some heterogeneity on the material properties of the steel bars or concrete quality of the beams can justify this difference.

The behaviour of VL3 beam was similar to the homologous beams of the previous series, having failed in shear. The sliding of the faces of the shear failure crack had a significant influence on the detachment of the concrete cover layer that including the strips (Fig. 14), which led to a premature loss of the potential strengthening of the NSM CFRP strips. The higher cross sectional area of tensile longitudinal bars, and the larger diameter of these bars, when compared to the reinforcements used in the previous series, promoted the dowel-effect, which contributed for the detachment of the concrete cover. However, in the VL3 beam, the sliding of the faces of the shear crack did not conduct to an abrupt detachment of the extremities of the strips, as happened in the corresponding beam of the previous series. In fact, in VL3 beam the strips were progressively expelled from their slits (Fig. 14).

Fig. 15a shows that the steel stirrup of VL3 beam, closest of the loaded section in the $L_{l}$ span, has ruptured, while the other stirrups loss their capability of embracing the longitudinal reinforcement (Fig. $15 b)$. This suggests that if beams with bottom arm steel stirrups cut for the installation of NSM strips are subjected to cyclic loadings, such in the case of a seismic occurrence, the steel stirrups can lose their capacity to provide shear resistance. In fact, in this case the applicability of the truss Mörsh approach, currently used for the evaluation of the contribution of tie stirrups and concrete compressive struts for the shear resistance of RC beams, is no more applicable. Furthermore, concrete confinement might be also too affected, which can have a detrimental effect, mainly when beams are also subjected to axial compressive force. These concerns advise extra research on the behaviour of RC beams with cut steel stirrups for the installation of NSM trips, subjected to cyclic loadings. The influence of fatigue loadings should also be investigated, since the load repetitions can significantly decrease the anchorage conditions 
of the cut arm branches of the stirrups, with the consequent adverse repercussions in terms of shear resistance and concrete confinement that steel stirrups can guaranty.

When designing the CFRP shear strengthening system for VLM3 beam, the recommendation [19] for a distance between consecutive strips of sheet $\left(s_{f}\right.$, Fig. 3) less than $0.9 d_{s}-w_{f} / 2\left(w_{f}\right.$ is the width of the strip of sheet, $d_{s}$ is the effective depth of the beam's cross section, $s_{f}=296 \mathrm{~mm}$ ) was disregarded. In this beam the distance between strips of sheet $\left(s_{f}=325 \mathrm{~mm}\right)$ was higher than the maximum value of $s_{f}$ recommended by [19], which contributed for the occurrence of a shear failure mode (Fig. 16).

From Table 4 and Fig. 16 it is verified that the increase in term of load carrying capacity provided by two laminates applied in VL3 beam $\left(\rho_{f}=0.076 \%\right)$ was $28 \%$, while the flexural and shear strengthening strategy adopted in VLM3 beam allowed an increase of $36 \%$. The results in this table also show that cutting the bottom arm of the steel stirrups of the beam of this Series led to a decrease of $11 \%$ in terms of beam's load carrying capacity. Although VLM3 beam failed in shear, at the maximum load the strain on the CFRP strip was $10 \%$, which is $56 \%$ of the material ultimate strain, similar to the value recorded in the corresponding beam of Series 1.

The strain fields in steel longitudinal bars and NSM CFRP strips were similar to those measured in the homologous beams of the previous series.

The relationship between the applied load and the strains recorded in the strain gauges applied in the intermediate strip of sheet is depicted in Fig. 17. In this beam, before the formation of the shear failure crack, another shear crack arose but it did not degenerate in a shear failure crack once it was crossed by the intermediate strip of sheet (see Fig. 10d and scheme inset of Fig. 17). Due to the fact that this crack has crossed this strip of sheet near $S G_{C V 8}$ (Fig. 17), the largest strain increment after the formation of this crack was observed in this strain gauge. With the widening process of this crack the resisting bond length of this strip of sheet was mobilized, resulting in a significant strain increment on the $S G_{C V 7}$ strain gauge. Since the resisting bond length of this strip of sheet avoided the degeneration of this shear crack into a shear failure crack, another shear crack formed in between the two strips of sheet closest the loaded section. When this shear crack crossed the intermediate strip of sheet at its bottom part, an abrupt increase of strain was registered in $S G_{C V 9}$. 


\section{Numerical model}

\subsection{Introduction}

Since diffuse flexural crack patterns were formed before the occurrence of the shear failure crack in the tested beams, smeared crack approach is an appropriate alternative to discrete and more sophisticated models whose values for the parameters of the corresponding constitutive models are difficult to obtain from the data that a designer can assess in real strengthening situations. Therefore, in the present work multi-directional fixed smeared crack model is adopted, having the values of the parameters of the constitutive model been obtained from the properties of the intervening materials that can be assessed from current practices of inspection and diagnosis in structural strengthening. It should be emphasized that the most important aspect of the numerical research carried out is the development of a very effective constitutive model to model beams failing in shear, since this is the crucial aspect for modelling with high accuracy (in a perspective of a designer) the behaviour of beams failing in shear. For this purpose a new formulation was developed to simulate the crack shear stress transfer. This new formulation, designated by "total" crack shear stress transfer, in an alternative to the already existing "incremental" crack shear stress transfer, was implemented in a FEM-based computer program.

\subsection{Multi-directional fixed smeared crack model}

Under the framework of the finite element analysis, the tested beams are considered as a plane stress problem. The description of the formulation of the multi-directional fixed smeared crack model is restricted to the case of cracked concrete, at the domain of an integration point $(I P)$ of a plane stress finite element. According to the adopted constitutive law, stress and strain are related by the following equation

$$
\Delta \underline{\sigma}=\underline{D}^{c r c o} \Delta \underline{\varepsilon}
$$

being $\Delta \underline{\sigma}=\left\{\Delta \sigma_{1}, \Delta \sigma_{2}, \Delta \tau_{12}\right\}^{T}$ and $\Delta \underline{\varepsilon}=\left\{\Delta \varepsilon_{1}, \Delta \varepsilon_{2}, \Delta \gamma_{12}\right\}^{T}$ the vectors of the incremental stress and incremental strain components.

Due to the decomposition of the total strain into an elastic concrete part and a crack part, $\Delta \underline{\varepsilon}=\Delta \underline{\varepsilon}^{c o}+\Delta \underline{\varepsilon}^{c r}$, [20], in Eq. (1) the cracked concrete constitutive matrix, $\underline{D}^{c r o}$, is obtained with the following equation [18]

$$
\underline{D}^{c r c o}=\underline{D}^{c o}-\underline{D}^{c o}\left[\underline{T}^{c r}\right]^{T}\left(\underline{D}^{c r}+\underline{T}^{c r} \underline{D}^{c o}\left[\underline{T}^{c r}\right]^{T}\right)^{-1} \underline{T}^{c r} \underline{D}^{c o}
$$

where $\underline{D}^{c o}$ is the constitutive matrix of concrete, assuming a linear behaviour 


$$
\underline{D}^{c o}=\frac{E_{c}}{1-v_{c}^{2}}\left[\begin{array}{ccc}
1 & v_{c} & 0 \\
v_{c} & 1 & 0 \\
0 & 0 & \frac{1-v_{c}}{2}
\end{array}\right]
$$

being $E_{c}$ and $v_{c}$ the elasticity modulus and the Poisson's ratio of concrete, respectively. In Eq. (2) $\underline{T}^{c r}$ is the matrix that transforms the stress components from the coordinate system of the finite element to the local crack coordinate system (a subscript $\ell$ is used to identify entities in the local crack coordinate system). If $m$ cracks occurs at an $I P$

$$
\underline{T}^{c r}=\left[\begin{array}{lllll}
\underline{T}_{1}^{c r} & \cdots & \underline{T}_{i}^{c r} & \cdots & \underline{T}_{m}^{c r}
\end{array}\right]^{T}
$$

being the matrix crack orientation of a generic $i^{\text {th }}$ crack defined by

$$
\underline{T}_{i}^{c r}=\left[\begin{array}{ccc}
\cos ^{2} \theta_{i} & \sin ^{2} \theta_{i} & 2 \sin \theta_{i} \cos \theta_{i} \\
-\sin \theta_{i} \cos \theta_{i} & \sin \theta_{i} \cos \theta_{i} & \cos ^{2} \theta_{i}-\sin ^{2} \theta_{i}
\end{array}\right]
$$

with $\theta_{i}$ being the angle between the $x_{l}$ axis and the vector orthogonal to the plane of the $i^{\text {th }}$ crack.

In Eq. (2) $\underline{D}^{c r}$ is a matrix that includes the constitutive law of the $m$ cracks

$$
\underline{D}^{c r}=\left[\begin{array}{ccccc}
\underline{D}_{1}^{c r} & \ldots & \underline{0} & \ldots & \underline{0} \\
\ldots & \ldots & \ldots & \ldots & \ldots \\
0 & \ldots & \underline{D}_{i}^{c r} & \ldots & \underline{0} \\
\ldots & \ldots & \ldots & \ldots & \ldots \\
0 & \ldots & \underline{0} & \ldots & \underline{D}_{m}^{c r}
\end{array}\right]
$$

with $\underline{D}_{i}^{c r}$ being the crack constitutive matrix of the $i^{\text {th }}$ crack

$$
\underline{D}_{i}^{c r}=\left[\begin{array}{cc}
D_{I, i}^{c r} & 0 \\
0 & D_{I I, i}^{c r}
\end{array}\right]
$$

where $D_{I, i}^{c r}$ and $D_{I I, i}^{c r}$ represent, respectively, the modulus correspondent to the fracture mode I (normal) and fracture mode II (shear) of the $i^{\text {th }}$ crack.

The crack system of an $I P$ is governed by the following relationship

$$
\Delta \underline{\sigma}_{\ell}^{c r}=\underline{D}^{c r} \Delta \underline{\varepsilon}_{\ell}^{c r}
$$

where $\Delta \underline{\sigma}_{\ell}^{c r}$ is the vector of the correspondent incremental crack stress components in the crack coordinate system

$$
\Delta \underline{\sigma}_{\ell}^{c r}=\left[\begin{array}{llllllll}
\Delta \sigma_{n, 1}^{c r} & \Delta \tau_{n t, 1}^{c r} & \ldots & \Delta \sigma_{n, i}^{c r} & \Delta \tau_{n t, i}^{c r} & \ldots & \Delta \sigma_{n, m}^{c r} & \Delta \tau_{n t, m}^{c r}
\end{array}\right]^{T}
$$

and $\Delta \underline{\varepsilon}_{\ell}^{c r}$ is the vector of the incremental crack strain components 


$$
\Delta \underline{\varepsilon}_{\ell}^{c r}=\left[\begin{array}{llllllll}
\Delta \varepsilon_{n, 1}^{c r} & \Delta \gamma_{n t, 1}^{c r} & \ldots & \Delta \varepsilon_{n, i}^{c r} & \Delta \gamma_{n t, i}^{c r} & \ldots & \Delta \varepsilon_{n, m}^{c r} & \Delta \gamma_{n t, m}^{c r}
\end{array}\right]^{T}
$$

Using the $\underline{T}^{c r}$ matrix, the vector of the incremental crack strain components in the finite element coordinate system, $\Delta \underline{\varepsilon}^{c r}$, can be obtained from $\Delta \underline{\varepsilon}_{\ell}^{c r}$

$$
\Delta \underline{\varepsilon}^{c r}=\left[\underline{T}^{c r}\right]^{T} \Delta \underline{\varepsilon}_{\ell}^{c r}
$$

and the equilibrium condition

$$
\Delta \underline{\sigma}_{\ell}^{c r}=\underline{T}^{c r} \Delta \underline{\sigma}
$$

must be assured.

In the present approach, a new crack is arisen in an $I P$ when the angle formed between the new crack and the already existing cracks, $\theta_{n e w}^{c r}$, exceeds a certain threshold angle, $\theta_{t h}$ (a parameter of the constitutive model that in general ranges between 30 and 60 degrees [20]).

The crack opening propagation is simulated with the trilinear diagram represented in Fig. 18, which is defined by the normalized stress, $\alpha_{i}$, and strain, $\xi_{i}$, parameters that define the transitions points between the linear segments of this diagram. The ultimate crack strain, $\varepsilon_{n, u}^{c r}$, is defined as a function of the parameters $\alpha_{i}$ and $\xi_{i}$, fracture energy, $G_{f}^{I}$, tensile strength, $f_{c t}=\sigma_{n, 1}^{c r}$, and crack band width, $l_{b}$, as follows [18],

$$
\varepsilon_{n, u}^{c r}=\frac{2}{\xi_{1}+\alpha_{1} \xi_{2}-\alpha_{2} \xi_{1}+\alpha_{2}} \frac{G_{f}^{I}}{f_{c t} l_{b}}
$$

being $\alpha_{1}=\sigma_{n, 2}^{c r} / \sigma_{n, 1}^{c r}, \alpha_{2}=\sigma_{n, 3}^{c r} / \sigma_{n, 1}^{c r}, \xi_{1}=\varepsilon_{n, 2}^{c r} / \varepsilon_{n, u}^{c r}$ and $\xi_{2}=\varepsilon_{n, 3}^{c r} / \varepsilon_{n, u}^{c r}$.

The fracture mode II modulus, $D_{I I}^{c r}$, is obtained with

$$
D_{I I}^{c r}=\frac{\beta}{1-\beta} G_{c}
$$

where $G_{c}$ is the concrete elastic shear modulus and $\beta$ is the shear retention factor. The parameter $\beta$ is defined as a constant value or as a function of the current crack normal strain, $\varepsilon_{n}^{c r}$, and of the ultimate crack normal strain, $\varepsilon_{n, u}^{c r}$, as follows,

$$
\beta=\left(1-\frac{\varepsilon_{n}^{c r}}{\varepsilon_{n, u}^{c r}}\right)^{p_{1}}
$$

When $p_{1}=1$ a linear decrease of $\beta$ with the increase of $\varepsilon_{n}^{c r}$ is assumed. Larger values of the exponent $p_{1}$ correspond to a more pronounced decrease of the parameter $\beta[18]$. 


\subsection{Incremental versus total approach for the crack shear stress-shear strain relationship}

The concept of the incremental and total approach for the crack shear stress-shear strain relationship is represented in Fig. 21. In the incremental approach the increment of the crack shear stress, $\Delta \tau_{n t}^{c r}$, is only null when $\varepsilon_{n}^{c r} \geq \varepsilon_{n, u}^{c r}$, ie, for $\beta=0$ (see Eq. (14)). Therefore, even if the crack opening is increasing, the crack shear stress, $\tau_{n t}^{c r}$, can also increase up to an asymptotic value, regardless of the fact that the crack is no longer capable of transferring normal tensile stresses. This can lead to the activation of the new crack opening criterion (maximum principal tensile stress, $\sigma_{I}$, greater than the stress crack initiation, $\sigma_{I}>\sigma_{n, I}^{c r}$, and $\theta_{\text {new }}^{c r}>\theta_{t h}$ ), resulting in several cracks at an $I P$, which introduces severe difficulties in accomplishing the correct current constitutive laws of the cracks formed in the $I P$, even if a rigorous straindecomposition concept is adopted for this purpose [18]. Another consequence is a numerical prediction of a load carrying capacity for the structural elements, mainly for those failing in shear, which is higher than the registered in experimental programs. The use of a softening law to model the crack shear stress transfer has also been explored with relative success in terms of the predictive performance of the behaviour of concrete elements failing in shear [21-23]. The presence of two softening laws for modelling the crack propagation, however, introduces extra numerical difficulties in terms of assuring numerical convergence [21].

The aim of the total approach, proposed in the present work, for modelling the fracture mode II, is to reproduce numerically a decrease of shear stress transfer $\left(\tau_{n t}^{c r}\right)$ with the increase of the crack sliding $\left(\gamma_{n t}^{c r}\right)$, as is expected when crack opening $\left(\varepsilon_{n}^{c r}\right)$ is also increasing (Fig. 19). This total approach for modelling the shear stress transfer, provided by aggregate interlock effect, was implemented into FEMIX computer program, a FEM-based software.

In the following sections the formulation of both the incremental and total approaches is described for the $k$ generic iteration of the stress updated algorithm (a subscript $k$ is added to the entities). A detailed description of the incremental approach can be found elsewhere [18].

\subsubsection{Incremental approach}

In the incremental approach, the two stress components at each crack, $\sigma_{n}^{c r}$ and $\tau_{n t}^{c r}$, are directly determined from their corresponding stress increments, $\Delta \sigma_{n}^{c r}$ and $\Delta \tau_{n t}^{c r}$. Introducing $\Delta \underline{\varepsilon}=\Delta \underline{\varepsilon}^{c o}+\Delta \underline{\varepsilon}^{c r}$ into Eq. (1) and using Eq. (11) yields 


$$
\Delta \underline{\sigma}_{k}=\underline{D}^{c o}\left(\Delta \underline{\varepsilon}_{k}-\left[\underline{T}_{k}^{c r}\right]^{T} \Delta \underline{\varepsilon}_{\ell, k}^{c r}\right)
$$

Eq. (12) can be written in the format

$$
\underline{\sigma}_{\ell, k-1}^{c r}+\Delta \underline{\sigma}_{\ell, k}^{c r}=\underline{T}_{k}^{c r}\left(\underline{\sigma}_{k-1}+\Delta \underline{\sigma}_{k}\right)
$$

Including Eq. (16) into Eq. (17) results

$$
\underline{\sigma}_{\ell, k-1}^{c r}+\Delta \underline{\sigma}_{\ell, k}^{c r}=\underline{T}_{k}^{c r}\left(\underline{\sigma}_{k-1}+\underline{D}^{c o}\left(\Delta \underline{\varepsilon}_{k}-\left[\underline{T}_{k}^{c r}\right]^{T} \Delta \underline{\varepsilon}_{\ell, k}^{c r}\right)\right)
$$

or

$$
\underline{\sigma}_{\ell, k-1}^{c r}+\Delta \underline{\sigma}_{\ell, k}^{c r}-\underline{T}_{k}^{c r} \underline{\sigma}_{k-1}-\underline{T}_{k}^{c r} \underline{D}^{c o} \Delta \underline{\varepsilon}_{k}+\underline{T}_{k}^{c r} \underline{D}^{c o}\left[\underline{T}_{k}^{c r}\right]^{T} \Delta \underline{\varepsilon}_{\ell, k}^{c r}=\underline{0}
$$

where $\Delta \underline{\sigma}_{\ell, k}^{c r}$ is obtained from $\Delta \underline{\varepsilon}_{\ell, k}^{c r}$ using Eq. (8). To solve the system of nonlinear equations represented in Eq. (19), where the unknowns are the components of the incremental crack strain vector $\Delta \underline{\varepsilon}_{\ell, k}^{c r}$, the Newton-Raphson method can be used and this development can be found elsewhere [18].

\subsubsection{Total approach}

The total approach is applied between the shear components. For this approach the Eq. (12) is rewritten in terms of total stresses (the formulation is restricted to one crack, but its generalization for $m$ cracks per each $I P$ is a straightforward process)

$$
\left[\begin{array}{c}
\sigma_{n, k-1}^{c r}+\Delta \sigma_{n, k}^{c r} \\
\tau_{n t, k}^{c r}
\end{array}\right]_{\ell}=\left[\begin{array}{ccc}
\cos ^{2} \theta & \sin ^{2} \theta & 2 \sin \theta \cos \theta \\
-\sin \theta \cos \theta & \sin \theta \cos \theta & \cos ^{2} \theta-\sin ^{2} \theta
\end{array}\right]_{k}\left(\left[\begin{array}{l}
\sigma \\
\tau
\end{array}\right]_{k-1}+\left[\begin{array}{c}
\Delta \sigma \\
\Delta \tau
\end{array}\right]_{k}\right)
$$

where

$$
\Delta \sigma_{n, k}^{c r}=D_{I, k}^{c r} \Delta \varepsilon_{n, k}^{c r}
$$

and

$$
\tau_{n t, k}^{c r}=D_{I I, k}^{c r} \gamma_{n t, k}^{c r}=D_{I I, k}^{c r}\left(\gamma_{n t, k-1}^{c r}+\Delta \gamma_{n t, k}^{c r}\right)=D_{I I, k}^{c r} \gamma_{n t, k-1}^{c r}+D_{I I, k}^{c r} \Delta \gamma_{n t, k}^{c r}
$$

Substituting Eqs. (21) and (22) in the left term of the Eq. (20) results

$$
\left[\begin{array}{c}
\sigma_{n, k-1}^{c r} \\
D_{I I, k}^{c r} \gamma_{n t, k-1}^{c r}
\end{array}\right]_{\ell}+\left[\begin{array}{c}
D_{I}^{c r} \Delta \varepsilon_{n}^{c r} \\
D_{I I}^{c r} \Delta \gamma_{n t}^{c r}
\end{array}\right]_{\ell, k}=\left[\begin{array}{ccc}
\cos ^{2} \theta & \sin ^{2} \theta & 2 \sin \theta \cos \theta \\
-\sin \theta \cos \theta & \sin \theta \cos \theta & \cos ^{2} \theta-\sin ^{2} \theta
\end{array}\right]_{k}\left(\left[\begin{array}{c}
\sigma \\
\tau
\end{array}\right]_{k-1}+\left[\begin{array}{c}
\Delta \sigma \\
\Delta \tau
\end{array}\right]_{k}\right)
$$

or in a matrix form

$$
\underline{\sigma}_{\ell, k-1}^{c r^{*}}+\Delta \underline{\sigma}_{\ell, k}^{c r}=\underline{T}_{k}^{c r}\left(\underline{\sigma}_{k-1}+\Delta \underline{\sigma}_{k}\right)
$$

and introducing Eq. (16) in Eq. (24) yields

$$
\underline{\sigma}_{\ell, k-1}^{c *}+\Delta \underline{\sigma}_{\ell, k}^{c r}-\underline{T}_{k}^{c r} \underline{\sigma}_{k-1}-\underline{T}_{k}^{c r} \underline{D}^{c o} \Delta \underline{\varepsilon}_{k}+\underline{T}_{k}^{c r} \underline{D}^{c o}\left[\underline{T}_{k}^{c r}\right]^{T} \Delta \underline{\varepsilon}_{\ell, k}^{c r}=\underline{0}
$$


Like in the incremental approach, $\Delta \underline{\varepsilon}_{\ell, k}^{c r}$ of Eq. (25) can be obtained applying the Newton-Raphson method.

\subsection{Constitutive laws for the steel bars and FRP materials}

For modelling the behaviour of the steel bars, the stress-strain relationship represented in Fig. 20 is adopted [18]. The curve (under compressive or tensile loading) is defined by the points $\mathrm{PT} 1=\left(\varepsilon_{s y}, \sigma_{s y}\right)$, $\mathrm{PT} 2=\left(\varepsilon_{s h}, \sigma_{s h}\right)$ and PT3 $=\left(\varepsilon_{s u}, \sigma_{s u}\right)$, and a parameter $p$ that defines the shape of the last branch of the curve. Unloading and reloading linear branches with slope $E_{s}\left(=\sigma_{s y} / \varepsilon_{s y}\right)$ are assumed in the present approach. To take into account that the stress in the steel reinforcement at the concrete crack plane is higher than the average stress determined in the $I P$ of the corresponding embedded cable element (the stress is obtained from the displacements of its mother element), the stress values of the PTi points defining the stress-strain relationship of the steel bars are reduced by the term $\Delta \sigma_{y c r}=75 f_{c t} / \phi_{s}$, as suggested by Stevens [24], being $f_{c t}$ the concrete tensile strength in $\mathrm{MPa}$, and $\phi_{s}$ the diameter of the steel bar in $\mathrm{mm}$.

For modelling both the NSM laminates and EBR strips of sheet, a linear elastic stress-strain relationship is adopted. These strengthening elements and the steel bar reinforcements are simulated by perfectly bonded embedded 1D finite elements. Previous numerical research demonstrated that this assumption is reasonable for NSM laminates, since for beams flexurally strengthened with NSM laminates of enough anchorage length, the slip is very small and the failure occurred due to the detachment of the concrete surrounding the laminates (rip-off failure mode) [17]. For the EBR strips of sheet this assumption can, however, be questionable, since debond can occur for strain levels in this composite that can be much less than its ultimate strain measured in uniaxial tensile tests. Taking into account that in the tested shear strengthened beams, the premature debond of the EBR strips almost coincided with the ultimate load of the beams, a perfect bond between EBR strips of sheet and concrete is assumed up to the localization of the shear failure crack crossing these strips $\left(\varepsilon_{n}^{c r} \geq \varepsilon_{n, u}^{c r}\right)$. The possibility of predicting with reasonable accuracy the behaviour of FRP strengthened RC beams adopting these simplified approaches are quite important in the designer perspective, since the evaluation of the bond stress-slip relationship for modelling the FRP-concrete interface of an existing RC structure is quite complex and still is a subject that deserves deep and specific research. The authors have considerable experience on this research topic [26-28] and recognize that the predictive performance of the numerical simulation strategy adopted in the present work can be very useful for designers involved in structural strengthening practice. 


\section{Numerical simulations}

\subsection{Finite element meshes and integration schemes}

The values of the parameters of the constitutive model used in the numerical simulations are indicated in Tables 2, 3 and $5\left(\Delta \sigma_{y c r}=18.8 \mathrm{MPa}, 14.1 \mathrm{MPa}, 11.2 \mathrm{MPa}\right.$ and $9.4 \mathrm{MPa}$ for $\phi 6, \phi 8, \phi 10$ and $\phi 12$, respectively). The concrete tensile strength and the fracture energy are obtained from the average compressive strength determined experimentally, and using the equations proposed by CEB-FIP Model Code 1993 [25]. Thus, deliberately, the authors assumed the typical designer framework in the structural strengthening of concrete structures, which, in general, only the basic properties of the intervening materials can be assessed. Therefore, the main purpose of the present strategy is to assess the predicting performance that can be attained with the developed model when the values of the parameters of the constitutive model are determined from the data derived from experimental tests carried out with specimens of the intervening materials.

The beams are modelled with a mesh of 8 node serendipity plane stress finite elements. The Gauss-Legendre integration scheme with $2 \times 2$ IP is used in all concrete elements. The steel bars, the NSM laminates and the EBR CFRP strips are modelled by 2 node perfect bonded embedded cables (one degree-of-freedom per each node).

\subsection{Results and discussion}

The experimental and the numerical (for both the total and incremental approaches) relationships between the load and the deflection at the loaded section for the beams of tested series are compared in Figs. 21 to 23. In these figures a horizontal line corresponding to the maximum experimental load (in dash-dot) is also included. The crack patterns of these beams at the end of the analysis (at the end of the last converged load increment) are represented in Figs. 24 to 26. The cracks are represented by quadrilateral 4-node finite elements centred at the integration points and have a width proportional to the crack normal strain, $\varepsilon_{n}^{c r}$.

Both numerical approaches simulated accurately the deformational response and the crack pattern of the VR and VE beams.

Both numerical approaches predicted with good accuracy the deformational response of the VL beams, but only the total approach captured with high precision the localization and profile of the shear failure crack (compare Figs. 24 to 26 and 10). 
At the moment of the shear failure, the longitudinal steel bars of the VL and VLM beams have already yielded, which is quite well predicted by both numerical models, since vertical completely open cracks are visible near the loaded section (Figs. 24 to 26). Fig. 27 shows that both numerical approaches predicted similar results but, after yield initiation, the predicted strains are lower than the strains measured experimentally. A possible explanation can be related to the fact that the SG could be at a position crossed by a flexural crack, thereby they registered an abrupt increase after yield initiation due to the gradient of strains in the crack plane. In the numerical simulations the concept of average strain is adopted, being the strains in the reinforcement obtained from the displacements of the corresponding mother element assuming a perfect bond between the materials. The Authors know that assuming a perfect bond between these materials is a simplified approach that can justify this non-optimum predictive performance. However, the degree of accuracy obtained with the performed numerical simulations is quite enough under the point of view of the structural strengthening design, and also taking into account the difficulties to obtain accurate values for modeling the constitutive law for interface elements, as well as the incomparable time consuming of these two distinct approaches.

Fig 27 also shows that the load at steel yield initiation is well predicted by the numerical models in the VL3 beam, while in VE3 beam a difference of about $10 \%$ is obtained. This indicates the probability of have occurred some deficiency in the construction of this last beam, which justifies the decrease of about $10 \%$ in the load carrying capacity of the VE3 beam, when compared to the maximum load supported by VR3 reference beam.

Up to the failure of the experimentally tested beams, Fig. 28 shows that both numerical simulations fit with good accuracy the average strains measured in the NSM laminates at the load section, which means that the assumption of perfect bond between composite materials and surrounding concrete is acceptable, at least in the design point of view for the serviceability and ultimate limit states.

The impossibility of achieving convergence in the VLM2 beam limited the maximum load at a value of $120.0 \mathrm{kN}$ and $142 \mathrm{kN}$ in the incremental and total approaches, while the ultimate load registered experimentally was $156 \mathrm{kN}$ (Fig. $28 \mathrm{~b} 2$ and Table 4). This predictive deficiency of the numerical models can be related to the failure mode observed in this beam (Fig. 10c). In fact, in the VLM2 beam, along the $L_{2}$ span (Fig. 2), the concrete cover layer that includes the NSM laminates has detached. To simulate numerically this type of failure mode, a 3D crack constitutive model needs to be used [22], but it requires too much more computing time than the models used in the present work, which is generally impractical in the design practice of structural strengthening. 
The force-deflection relationships of Figs. 21 to 23 and the crack patterns represented in Figs. 24 to 26 show that the total approach assures better simulations of the beams failing in shear and flexural/shear.

\section{Conclusions}

The influence in terms of RC beam's load carrying capacity of cutting steel stirrups to install CFRP laminates for the flexural strengthening of RC beams according to the NSM technique was assessed by carrying out an experimental and a numerical research program.

From the results obtained in the experimental tests, the following conclusions can be pointed out:

- For beams subject to an increasing monotonic loading, and with a percentage of steel stirrups higher than the minimum one, cutting the bottom arm of the steel stirrups for the installation of CFRP strips led to a decrease in terms of beam's load carrying capacity lower than $10 \%$, when the corresponding reference beam (with intact steel stirrups) was considered for comparison purposes;

- In RC beams with a longitudinal steel reinforcement ratio of about $0.4 \%$, which is significantly higher than the minimum percentage, an increment of the beam's load carrying capacity larger than $50 \%$ can be obtained applying CFRP strips according to the NSM technique, even in beams with the bottom arm of the steel stirrups cut for the installation of these strips. However, this strengthening performance can only be attained if the shear failure of the beam and the premature detachment of the concrete cover that includes the CFRP strips are avoided. These both types of failure modes can be avoided applying $\mathrm{U}$ or $\mathrm{O}$ (full wrapping) shear strengthening configurations composed by strips of CFRP wet lay-up sheet, according to the EBR technique, in a percentage and with strip's spacing recommended by fib or ACI guidelines.

A total crack shear stress-shear strain approach was implemented in a multi-directional fixed smeared crack model for a better simulation of the strengthened beams failing in shear and in flexural/shear modes. This approach is able of simulating the decrease of the total crack shear stress with the crack opening. For the numerical simulation of the NSM flexurally strengthened beams, the NSM laminates can be assumed as perfectly bonded to the surrounding concrete. Quite good predictions of the deformational behaviour and crack pattern of the tested beams were obtained, even when the values of the parameters of the constitutive model are directly determined from the results obtained in experimental tests with specimens of the involved materials, which is the current source of data that a designer has in structural strengthening practice. 
The influence of cyclic and fatigue loadings on the strengthening effectiveness of RC beams with cut steel stirrups for the installation of NSM CFRP strips needs to be addressed by specific research programs.

\section{Acknowledgements}

The study reported in this paper forms a part of the research program "CUTINEMO - Carbon fiber laminates applied according to the near surface mounted technique to increase the flexural resistance to negative moments of continuous reinforced concrete structures" supported by FCT, PTDC/ECM/73099/2006. The authors wish to acknowledge the support also provided by the S\&P, Casais and Artecanter Companies. The second Author acknowledges the grant under the aforementioned research project. The third author acknowledges the financial support of FCT, PhD Grant number SFRH/BD/23326/2005.

\section{References}

[1] Barros JAO, Fortes AS. Flexural strengthening of concrete beams with CFRP laminates bonded into slits. Journal Cement and Concrete Composites 2005; 27(4): 471-480.

[2] El-Hacha R, Rizkalla SH. Near-surface-mounted fiber-reinforced polymer reinforcements for flexural strengthening of concrete structures. ACI Structural Journal 2004; 101(5): 717-726.

[3] Liu IST, Oehlers DJ, Seracino R. Tests on the ductility of reinforced concrete beams retrofitted with FRP and steel near-surface mounted plates. Journal of Composites for Construction 2006; 10(2): 106-114.

[4] Täljsten B, Carolin A, Nordin H. Concrete structures strengthened with near surface mounted reinforcement of CFRP. Advances in Structural Engineering 2003; 6(3): 201-213.

[5] Kotynia R. Strain efficiency of near surface mounted CFRP-strengthened reinforced concrete beams. Proc. of CCC conference, 11-13, Lyon, France, 2005.

[6] Bonaldo E, Barros JAO, Lourenço PJB. Efficient strengthening technique to increase the flexural resistance of existing RC slabs. Journal of Composites for Construction 2008; 12(2): 149-159.

[7] Barros JAO, Dalfré GM, Dias JPSE. "Numerical Simulation of Continuous RC Slabs Strengthened using NSM Technique. $2^{\text {nd }}$ International Conference on Concrete Repair, Rehabilitation and Retrofitting (ICCRRR 2008), 24-26 November 2008. 
[8] Haskett MH, Oehlers DJ, Wu C. Improved IC debonding resistance of embedded NSM FRP plates. Asia-Pacific Conference on FRP in Structures, APFIS 2007.

[9] Bianco V. Shear strengthening of RC beams by means of NSM CFRP strips: experimental evidence and analytical modelling. PhD Thesis, Sapienza University of Rome, April 2009.

[10] Kotynia R. Analysis of reinforced concrete beams strengthened with near surface mounted FRP reinforcement. Archives of Civil Engineering, LII 2, 2006. p. 305-317.

[11] Barros JAO, Kotynia R. Possibilities and challenges of NSM for the flexural strengthening of RC structures. Fourth International Conference on FRP Composites in Civil Engineering (CICE2008), Zurich, Switzerland, 22-24 July 2008.

[12] Barros JAO, Dias SJE, Lima JLT. Efficacy of CFRP-based techniques for the flexural and shear strengthening of concrete beams. Journal Cement and Concrete Composites 2007; 29(3): 203-217.

[13] Barros JAO, Dias SJE, Lima JLT. Analytical and numerical analysis of the behaviour of RC beams flexural strengthened with CFRP. Fourth International Conference on FRP Composites in Civil Engineering (CICE2008), Zurich, Switzerland, 22-24 July 2008.

[14] ACI Committee 440. Guide for the design and construction of externally bonded FRP systems for strengthening concrete structures. American Concrete Institute, 118 p., 2007.

[15] Lima JLT, Barros JAO. Design models for shear strengthening of reinforced concrete beams with externally bonded FRP composites: a statistical vs. reliability approach. FRPRCS-8, University of Patras, Patras, Greece, July 16-18 2007.

[16] Sas G, Täljsten B, Barros JAO, Lima JLT, Carolin A. Are available models reliable for predicting the FRP contribution to the shear resistance of RC beams?. In press, ASCE Composites for Construction Journal.

[17] Sena-Cruz JM, Barros JAO, Azevedo AFM, Ventura-Gouveia A. Numerical simulation of the nonlinear behavior of RC beams strengthened with NSM CFRP strips. CMNE/CILAMCE, FEUP, Porto, 13-15 June 2007.

[18] Sena-Cruz JM. Strengthening of concrete structures with near-surface mounted CFRP laminate strips. PhD Thesis, Department of Civil Engineering, University of Minho. http://www.civil.uminho.pt/composites, 2004.

[19] fib - Bulletin 14. Externally bonded FRP reinforcement for RC structures. Technical report by Task Group 9.3 FRP, 130, 2001. 
[20] Rots JG. Computational modeling of concrete fracture. PhD Thesis, Delft University of Technology, 1988.

[21] Rots JG, de Borst R. Analysis of mixed-mode fracture in concrete. Journal of Engineering Mechanics-ASCE 1987; 113(11): 1739-1758.

[22] Ventura-Gouveia A, Barros JAO, Azevedo AFM, Sena-Cruz JM. Multifixed smeared 3D crack model to simulate the behavior of fiber reinforced concrete structures. Challenges for Civil Construction International Conference (CCC2008), Porto, Portugal, 16-18 April 2008.

[23] Santos PFS, Barros JAO, Lourenço LAP. Steel fibres for the shear resistance of high strength concrete beams. BEFIB 2008, 7th RILEM International Symposium on Fibre Reinforced Concrete Design and Applications, Paper SIM01, 17-19 September 2008.

[24] Stevens NJ. Analytical modelling of reinforced concrete subjected to monotonic and reversed loadings. Publication No. 87-1, ISBN 0-7727-7088-3, University of Toronto, January 1987.

[25] CEB-FIP Model Code. Comite Euro-International du Beton, Bulletin d'Information n ${ }^{\text {o }}$ 213/214, 1993.

[26] Sena-Cruz, J.M.; Barros, J.A.O., "Bond between near-surface mounted CFRP laminate strips and concrete in structural strengthening”, Journal of Composites for Construction, 8(6), p. 519-527, 2004.

[27] Sena-Cruz, J.M.; Barros, J.A.O., "Modeling of bond between near-surface mounted CFRP laminate strips and concrete", Computers and Structures Journal, 82(17-19), p. 1513-1521, 2004.

[28] Sena-Cruz, J.M.; Barros, J.A.O.; Azevedo, A.F,M.; Gettu, R., "Bond behavior of near-surface mounted CFRP laminate strips under monotonic and cyclic loading”, Journal of Composites for Construction, 10(4), 295-303, Julho/Agosto 2006. 


\section{NOTATION}

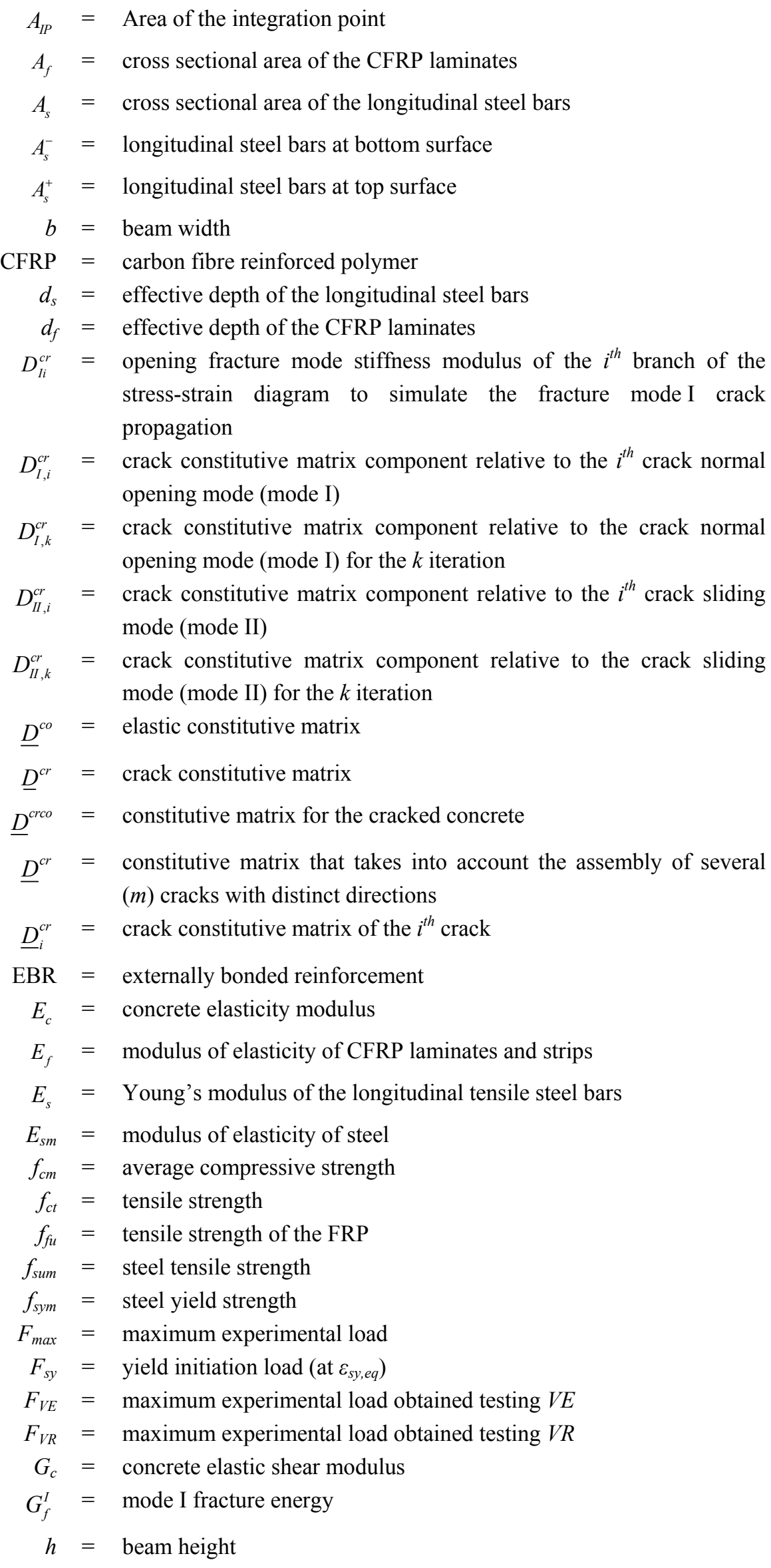




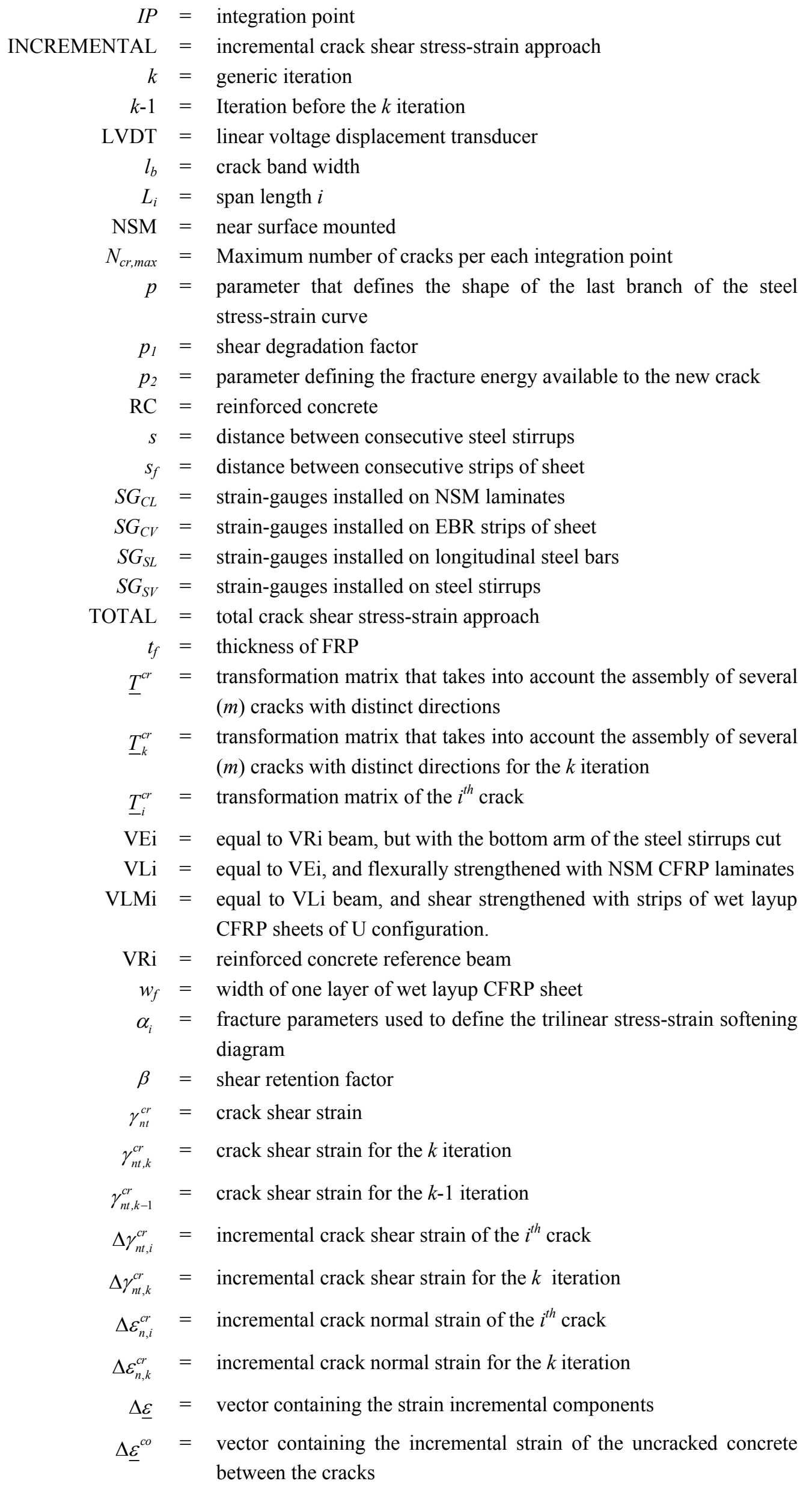




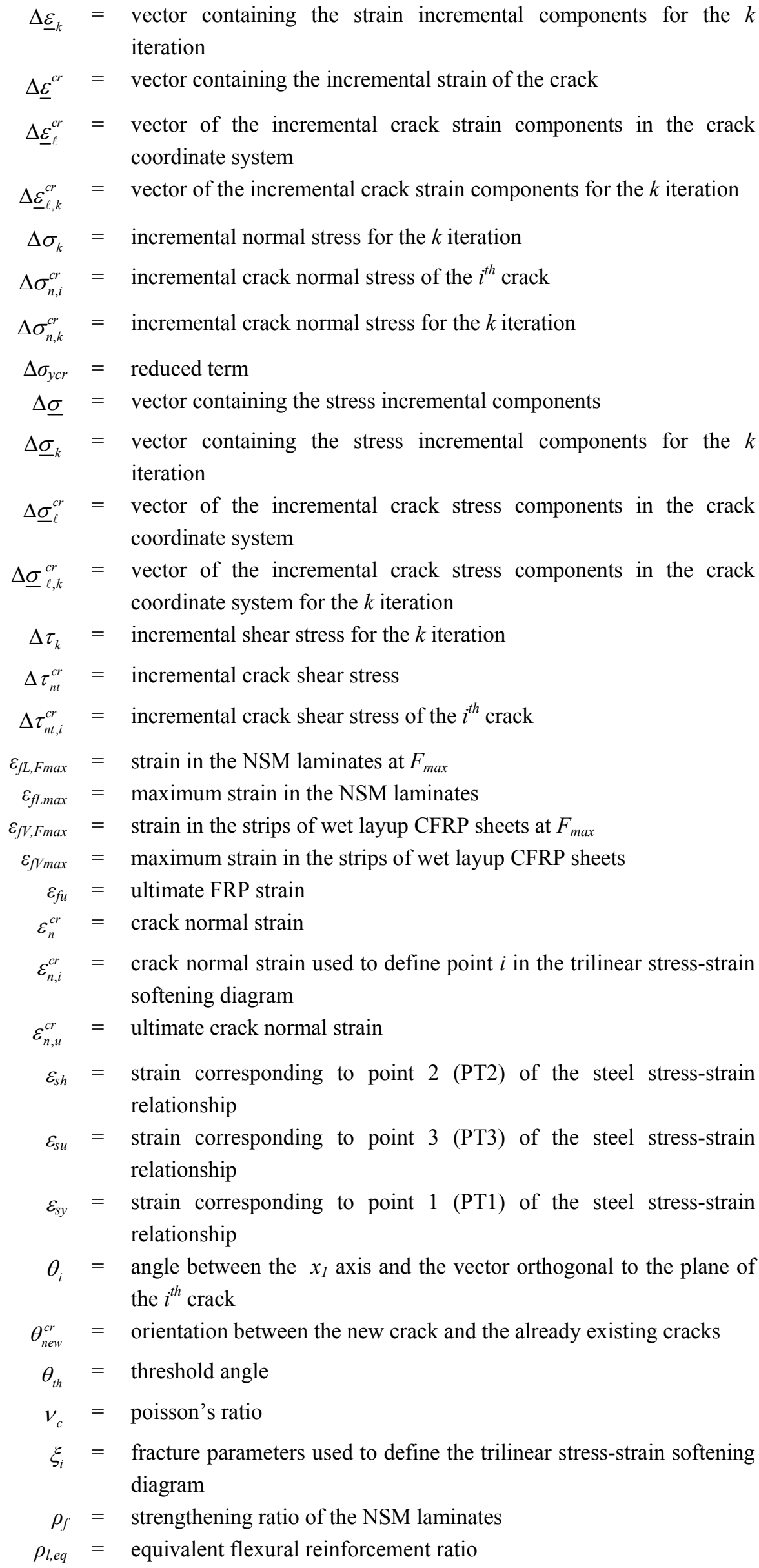




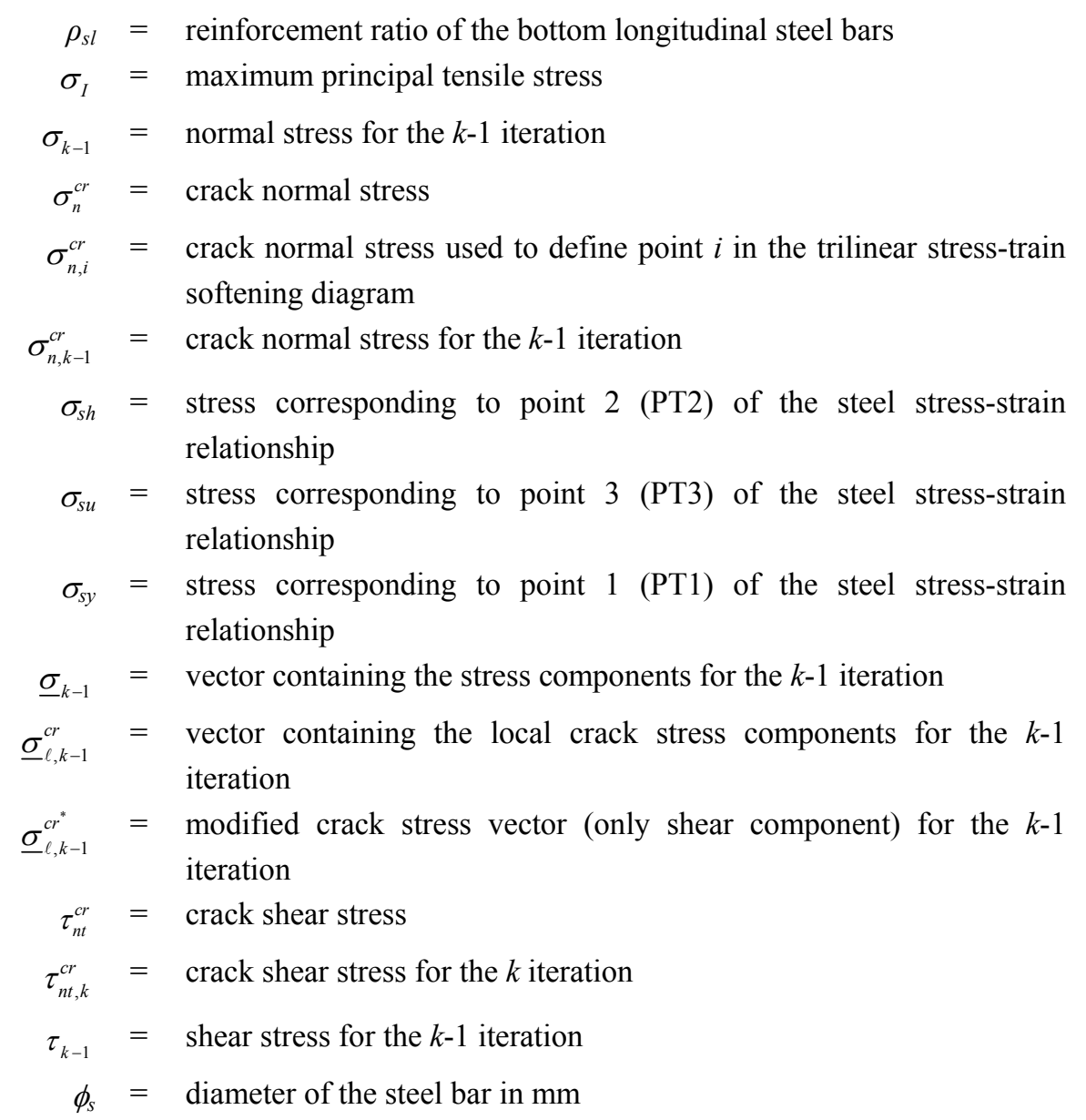




\section{Figure Captions}

Fig. 1. Rip-off failure mode: a) photo [1]; b) schematic representation.

Fig. 2. Beam geometry, support and loading conditions - see Table 1 (dimensions in mm).

Fig. 3. Representation of the flexural and shear strengthening systems (dimensions in $\mathrm{mm}$ ).

Fig. 4. Localization of the strain gauges installed on a steel stirrup $\left(S G_{S V}\right)$ and on a longitudinal steel bar $\left(S G_{S L}\right)$ (dimensions in $\left.\mathrm{mm}\right)$.

Fig. 5. Localization of the strain gauges installed on the NSM CFRP laminates $\left(S G_{C L}\right)$ and on the EBR strip of wet layup CFRP sheet $\left(S G_{C V}\right)$ (dimensions in $\left.\mathrm{mm}\right)$.

Fig. 6 - Deflection-load relationship for the beams of Series 1.

Fig. 7 - Relationship between the strains in the longitudinal steel bars $\left(S G_{S L 1}\right)$ and the applied load.

Fig. 8 - Relationship between the applied load and the strains in both the longitudinal steel bars $\left(S G_{S L 1}\right)$ and NSM strips $\left(S G_{C L 1,2}\right)$.

Fig. 9 - Relationship between the strains in the EBR strip of sheet $\left(S G_{C V 1}, S G_{C V 2}, S G_{C V 3}\right)$ and the applied load, in VLM1 beam (dimensions in $\mathrm{mm}$ ).

Fig. 10. Crack patterns at the end of the tested beams: (a) VL1, (b) VL2, (c), VLM2 (d) VLM3.

Fig. 11 - Crack pattern of the bottom surface of the VLM2 beam along the $L_{2}$ span, at the end of the test.

Fig. 12 - Deflection-load relationship for the beams of Series 2.

Fig. 13 - Relationship between the strains in the EBR strip of sheet $\left(S G_{C V 4}, S G_{C V 5}, S G_{C V 6}\right)$ and the applied load, in VLM2 beam (dimensions in $\mathrm{mm}$ ).

Fig 14 - Evolution of the expulsion of the strips of VL3 beam.

Fig. 15 - VL3 beam: a) failure of the stirrup closest of the loaded section; b) Sliding of the central stirrup on the $L_{l}$ span.

Fig. 16 - Deflection-load relationship for the beams of Series 3.

Fig. 17 - Relationship between the strains in the EBR strip of sheet $\left(S G_{C V 7}, S G_{C V 8}, S G_{C V 9}\right)$ and the applied load, in VLM3 beam (dimensions in $\mathrm{mm}$ ).

Fig. 18. Trilinear stress-strain diagram to simulate the fracture mode I crack propagation $\left(\sigma_{n, 2}^{c r}=\alpha_{I} \sigma_{n, I}^{c r}\right.$, $\left.\sigma_{n, 3}^{c r}=\alpha_{2} \sigma_{n, 1}^{c r}, \varepsilon_{n, 2}^{c r}=\xi_{1} \varepsilon_{n, u}^{c r}, \varepsilon_{n, 3}^{c r}=\xi_{2} \varepsilon_{n, u}^{c r}\right)$.

Fig. 19. Relation between crack shear stress and crack shear strain for the incremental and total approaches.

Fig. 20. Uniaxial constitutive model of the steel bars.

Fig. 21. Load-deflection at the loaded section for the beams of Series 1.

Fig. 22. Load-deflection at the loaded section for the beams of Series 2. 
Fig. 23. Load-deflection at the loaded section for the beams of Series 3.

Fig. 24. Crack patterns of the beams of Series 1 (in pink colour: crack completely open $\left(\varepsilon_{n}^{c r} \geq \varepsilon_{n, u}^{c r}\right)$; in red colour: crack in the opening process; in cyan colour: crack in reopening process).

Fig. 25. Crack patterns of the beams of Series 2 (in pink colour: crack completely open $\left(\varepsilon_{n}^{c r} \geq \varepsilon_{n, u}^{c r}\right)$; in red colour: crack in the opening process; in cyan colour: crack in reopening process).

Fig. 26. Crack patterns of the beams of Series 3 (in pink colour: crack completely open $\left(\varepsilon_{n}^{c r} \geq \varepsilon_{n, u}^{c r}\right)$; in red colour: crack in the opening process; in cyan colour: crack in reopening process).

Fig. 27. Relationship between the strains in the longitudinal steel bars $\left(S G_{S L}\right)$ and the applied load for the beams of Series 3 .

Fig. 28. Relationship between the strains in the NSM CFRP laminates $\left(S G_{C L 1,2}\right)$ and the applied load for the beams: (a1) VL1 and (b1) VLM1; (a2) VL2 and (b2) VLM2; (a3) VL3 and (b3) VLM3. 


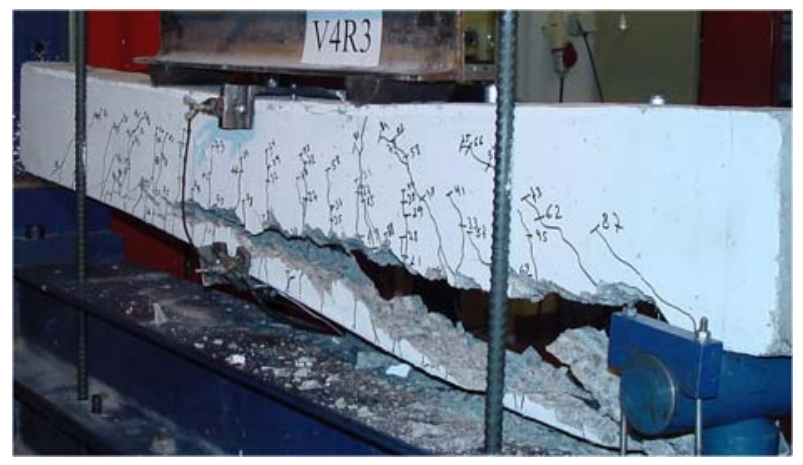

a)
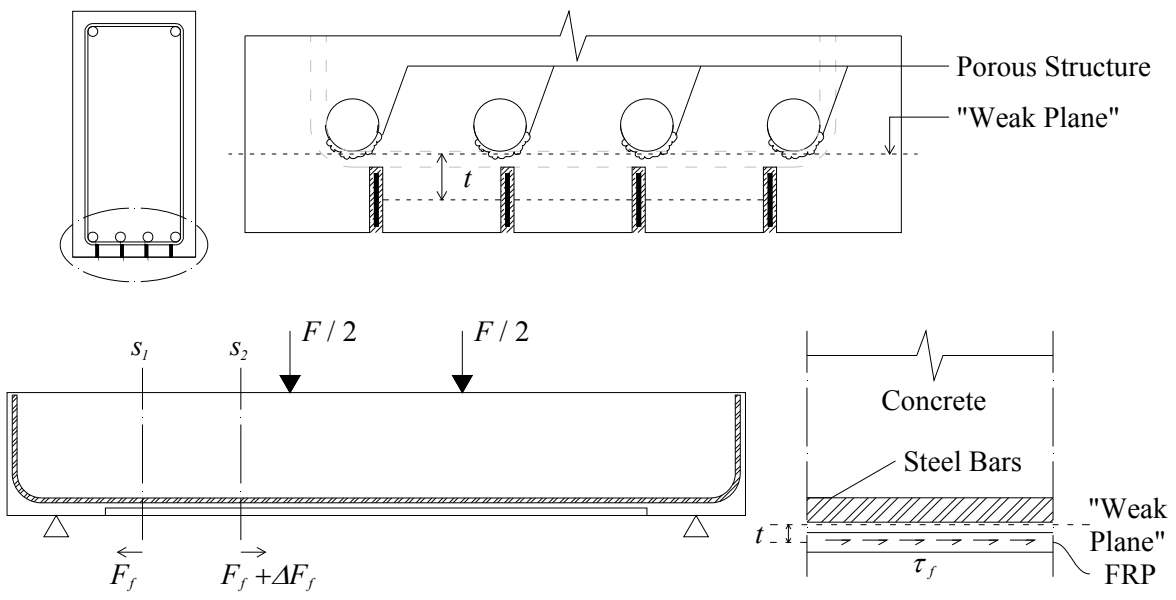

b)

Fig. 1. Rip-off failure mode: a) photo [1]; b) schematic representation. 


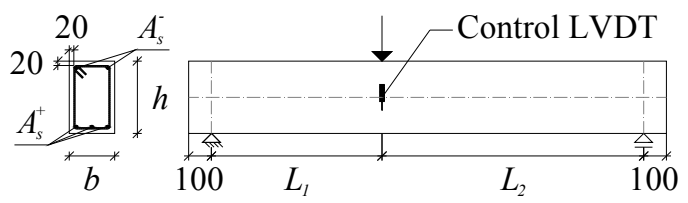

Fig. 2. Beam geometry, support and loading conditions - see Table 1 (dimensions in mm). 


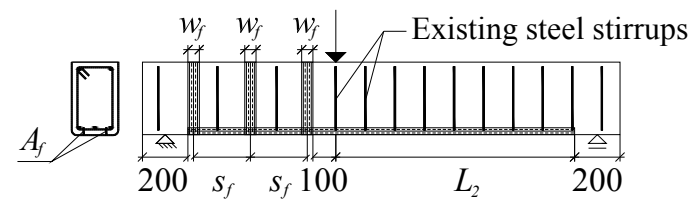

Fig. 3. Representation of the flexural and shear strengthening systems (dimensions in $\mathrm{mm}$ ). 


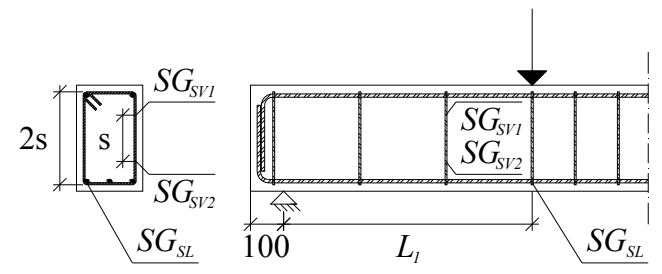

Fig. 4. Localization of the strain gauges installed on a steel stirrup $\left(S G_{S V}\right)$ and on a longitudinal steel bar $\left(S G_{S L}\right)$ (dimensions in $\left.\mathrm{mm}\right)$. 


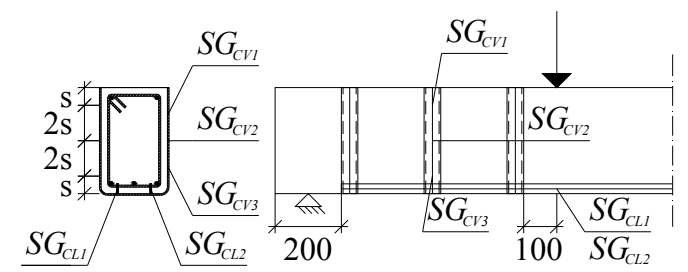

Fig. 5. Localization of the strain gauges installed on the NSM CFRP laminates $\left(S G_{C L}\right)$ and on the EBR strip of wet layup CFRP sheet $\left(S G_{C V}\right)$ (dimensions in $\mathrm{mm}$ ). 


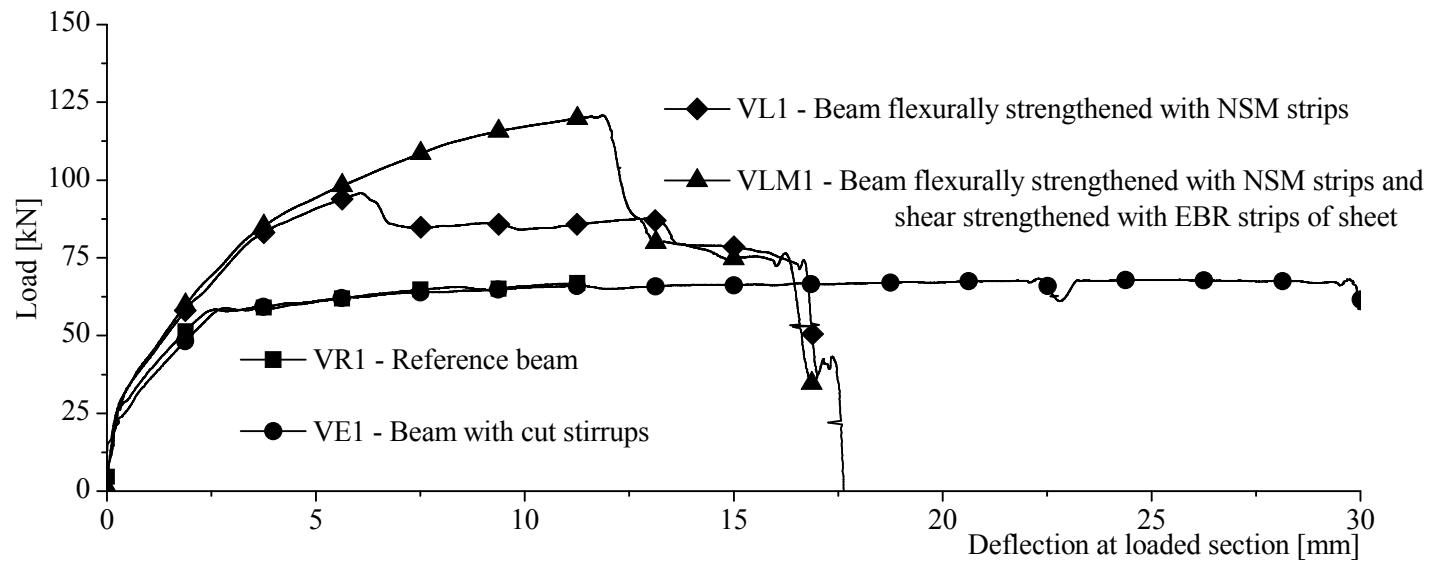

Fig. 6 - Deflection-load relationship for the beams of Series 1. 


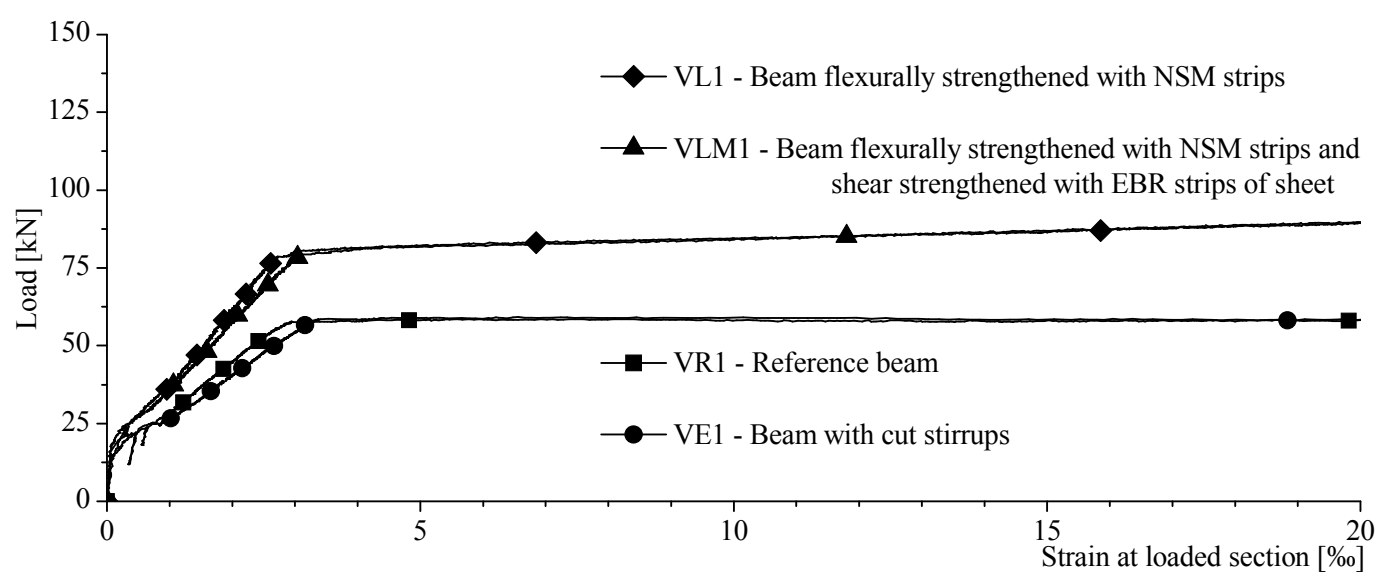

Fig. 7 - Relationship between the strains in the longitudinal steel bars $\left(S G_{S L I}\right)$ and the applied load. 


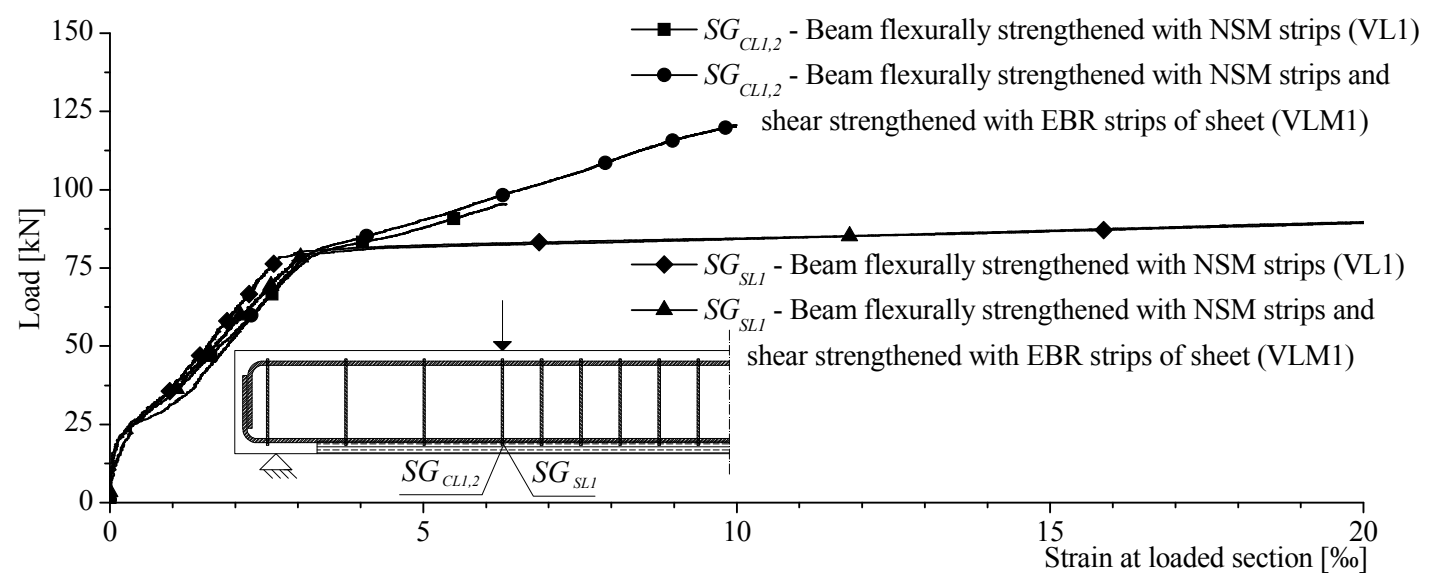

Fig. 8 - Relationship between the applied load and the strains in both the longitudinal steel bars $\left(S G_{S L I}\right)$ and NSM strips $\left(S G_{C L 1,2}\right)$. 


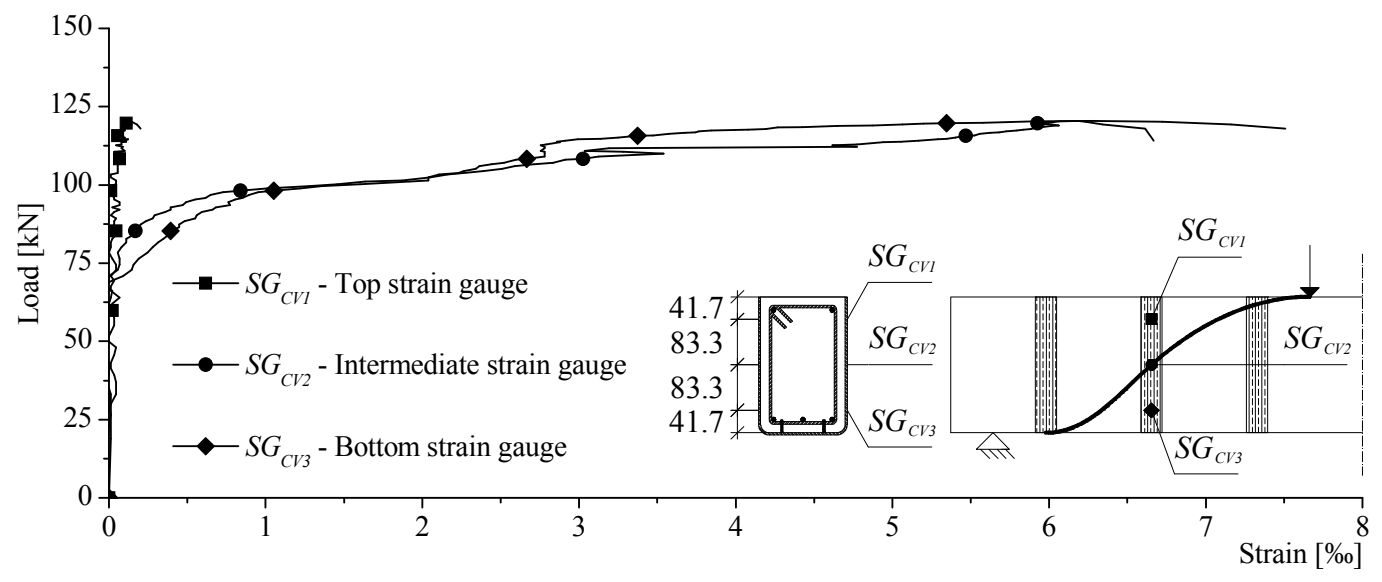

Fig. 9 - Relationship between the strains in the EBR strip of sheet $\left(S G_{C V 1}, S G_{C V 2}, S G_{C V 3}\right)$ and the applied load, in VLM1 beam (dimensions in $\mathrm{mm}$ ). 


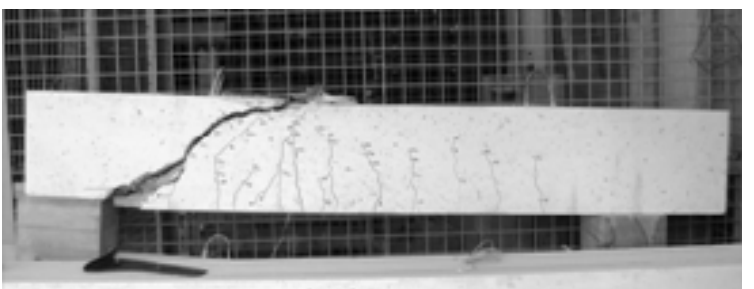

(a) VL1

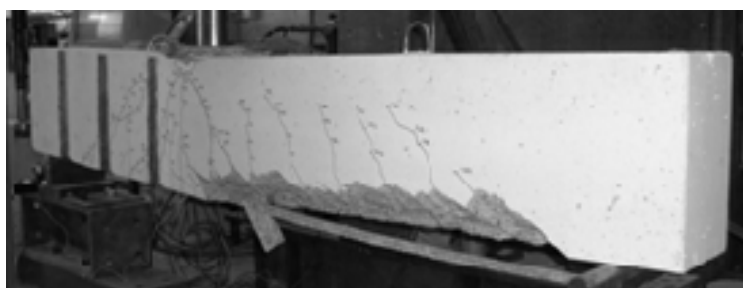

(c) - VLM2

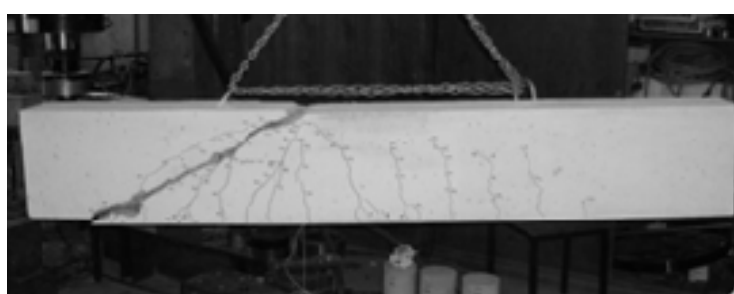

(b) - VL2

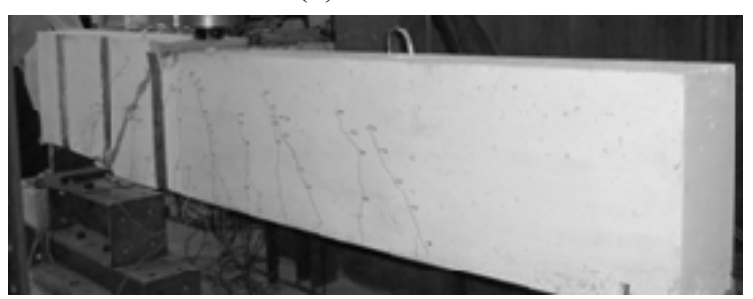

(d) - VLM3

Fig. 10. Crack patterns at the end of the tested beams: (a) VL1, (b) VL2, (c), VLM2 (d) VLM3. 


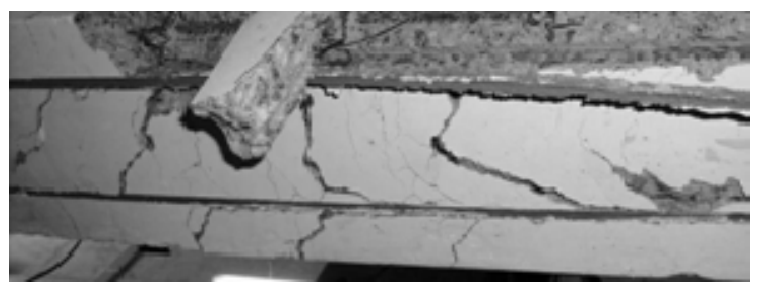

Fig. 11 - Crack pattern of the bottom surface of the VLM2 beam along the $L_{2}$ span, at the end of the test. 


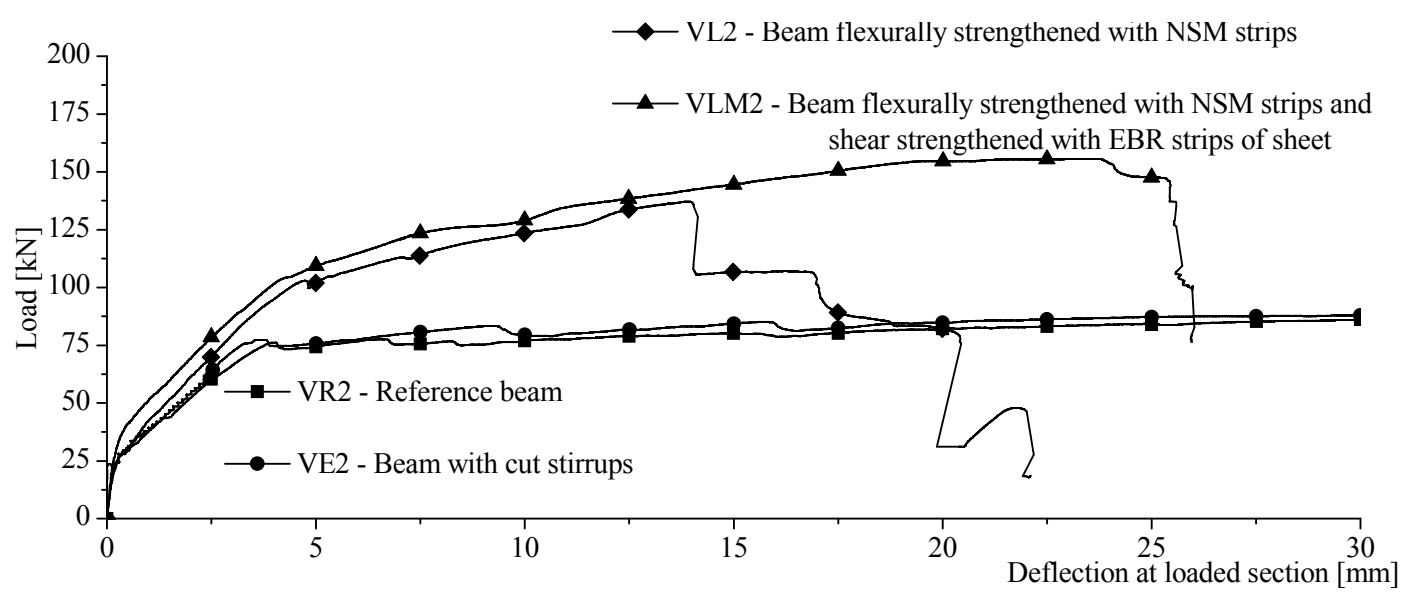

Fig. 12 - Deflection-load relationship for the beams of Series 2. 


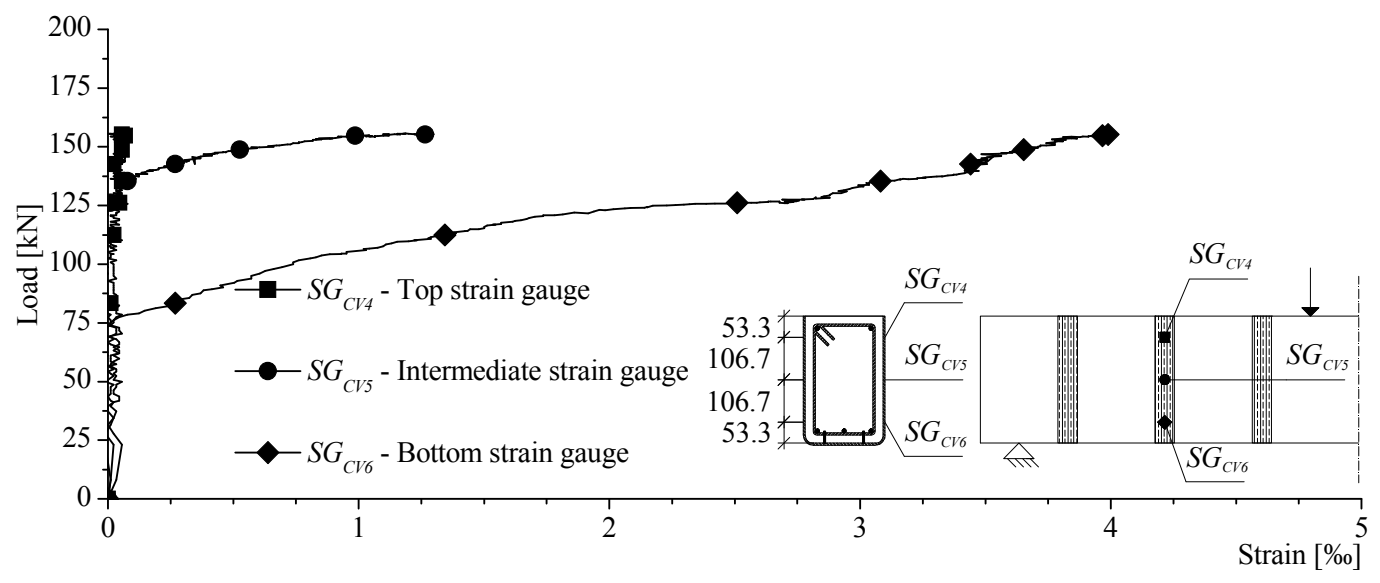

Fig. 13 - Relationship between the strains in the EBR strip of sheet $\left(S G_{C V 4}, S G_{C V 5}, S G_{C V 6}\right)$ and the applied load, in VLM2 beam (dimensions in $\mathrm{mm}$ ). 


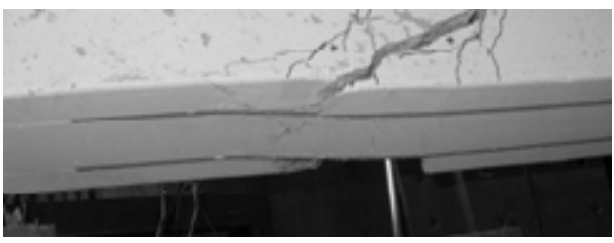

(a)

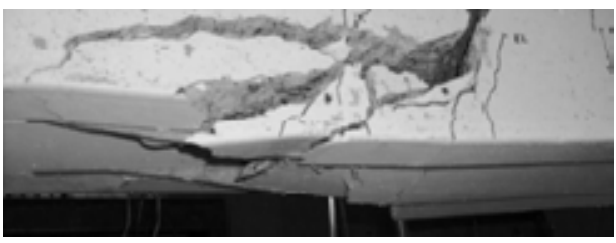

(b)

Fig 14 - Evolution of the expulsion of the strips of VL3 beam. 


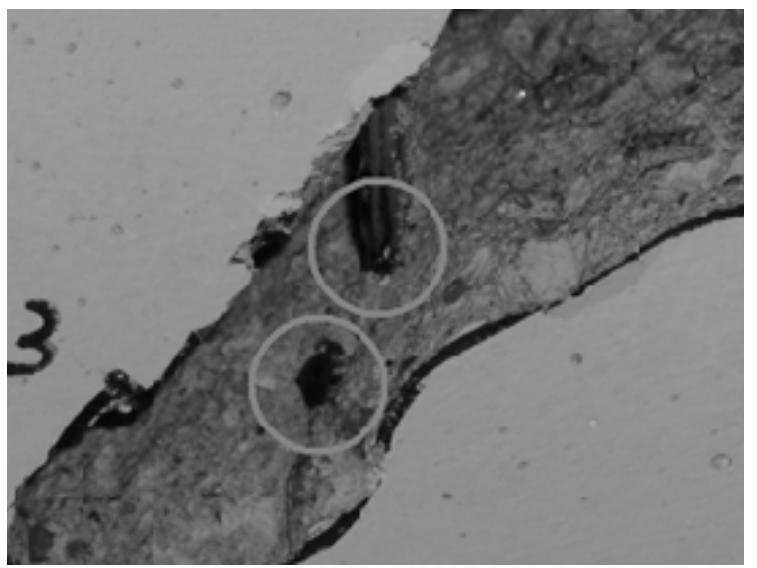

a)

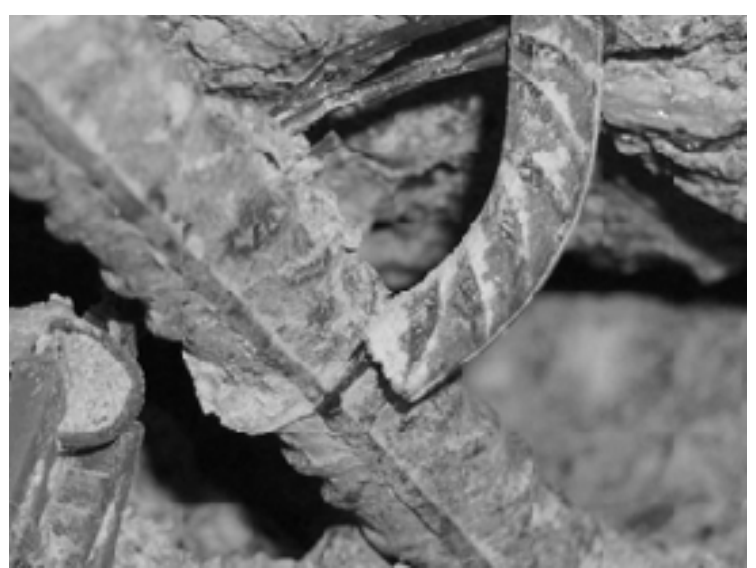

b)

Fig. 15 - VL3 beam: a) failure of the stirrup closest of the loaded section; b) Sliding of the central stirrup on the $L_{1}$ span. 


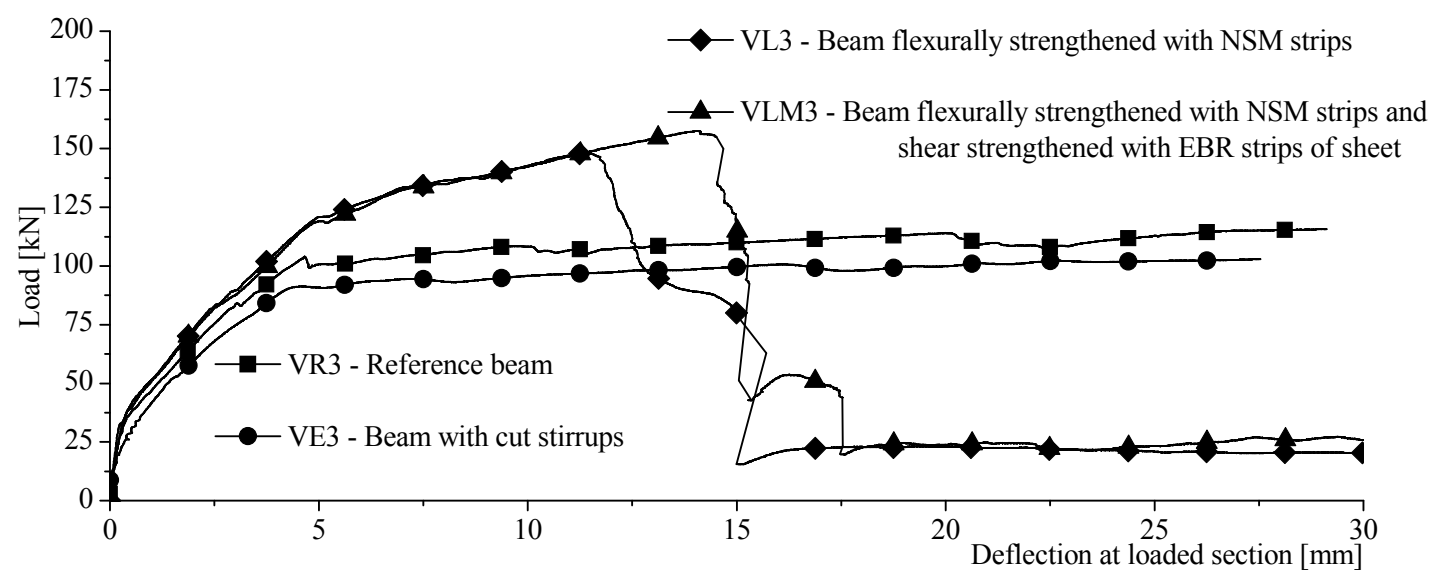

Fig. 16 - Deflection-load relationship for the beams of Series 3. 


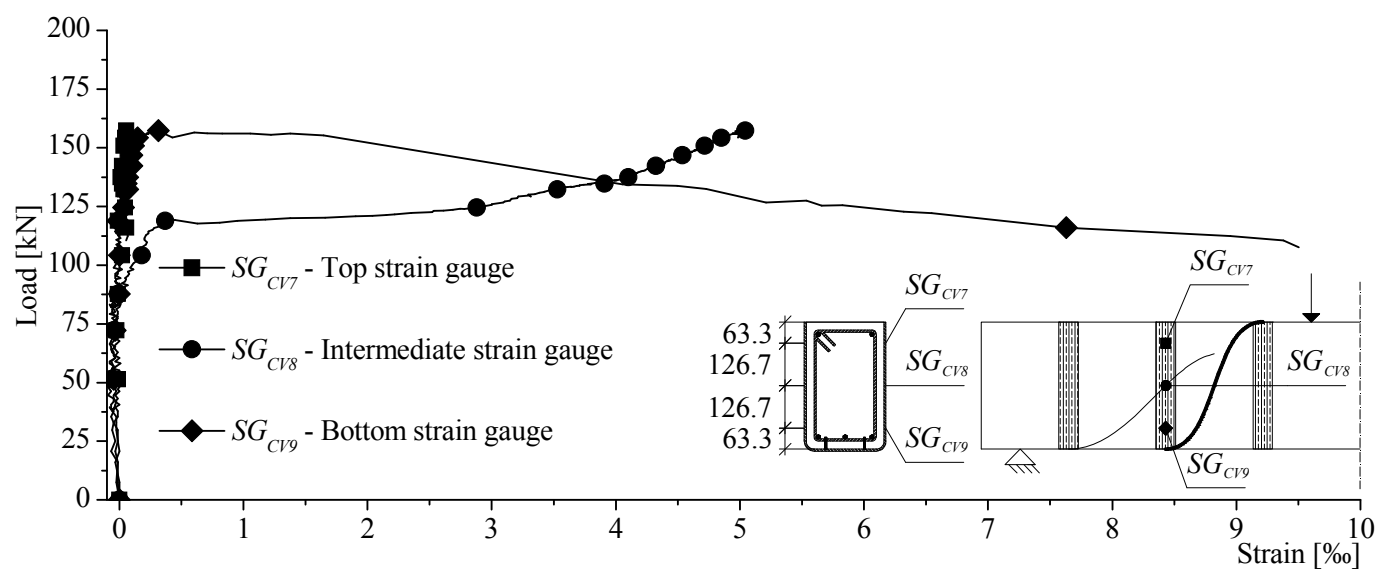

Fig. 17 - Relationship between the strains in the EBR strip of sheet $\left(S G_{C V 7}, S G_{C V 8}, S G_{C V 9}\right)$ and the applied load, in VLM3 beam (dimensions in mm). 


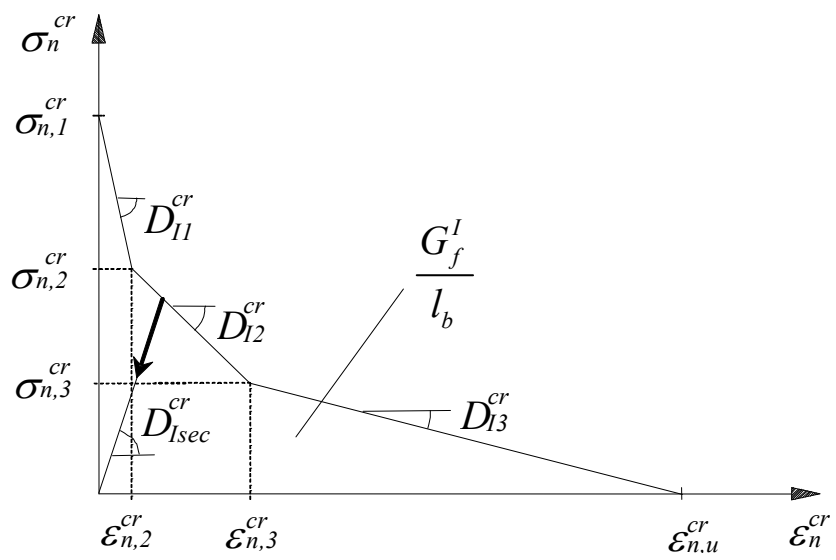

Fig. 18. Trilinear stress-strain diagram to simulate the fracture mode I crack propagation ( $\sigma_{n, 2}^{c r}=\alpha_{1} \sigma_{n, 1}^{c r}$, $\left.\sigma_{n, 3}^{c r}=\alpha_{2} \sigma_{n, 1}^{c r}, \varepsilon_{n, 2}^{c r}=\xi_{1} \varepsilon_{n, u}^{c r}, \varepsilon_{n, 3}^{c r}=\xi_{2} \varepsilon_{n, u}^{c r}\right)$. 


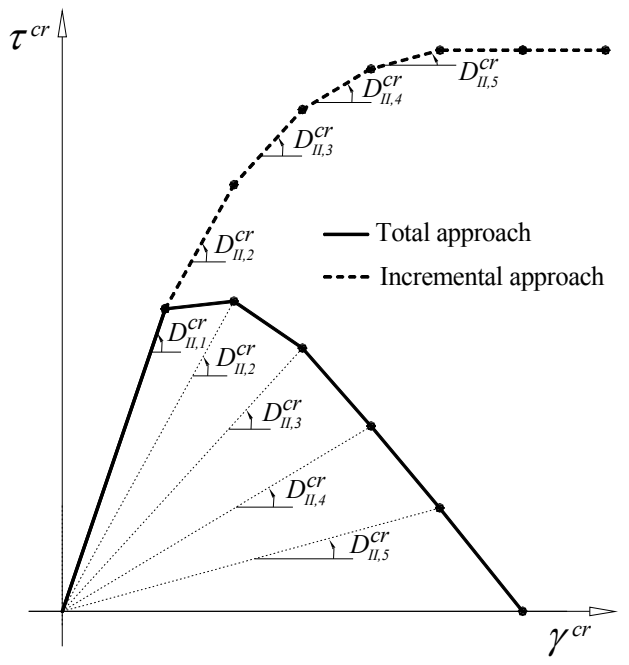

Fig. 19. Relation between crack shear stress and crack shear strain for the incremental and total approaches. 


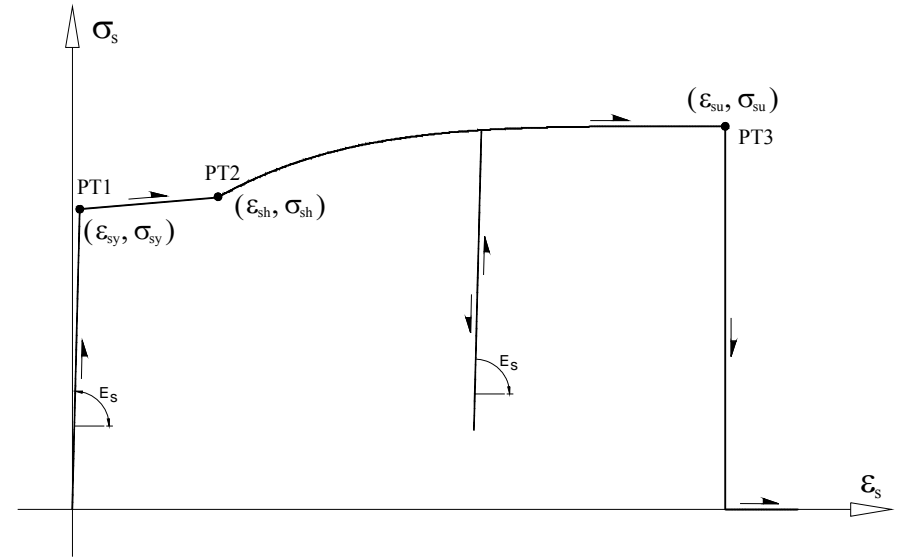

Fig. 20. Uniaxial constitutive model of the steel bars. 


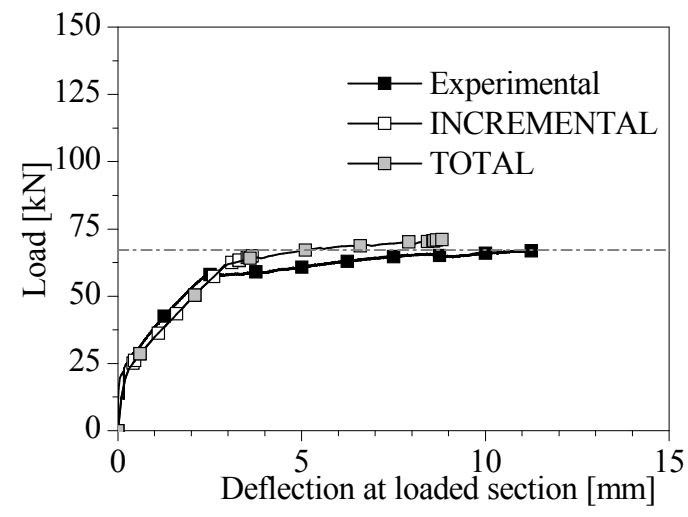

(a) - VR1

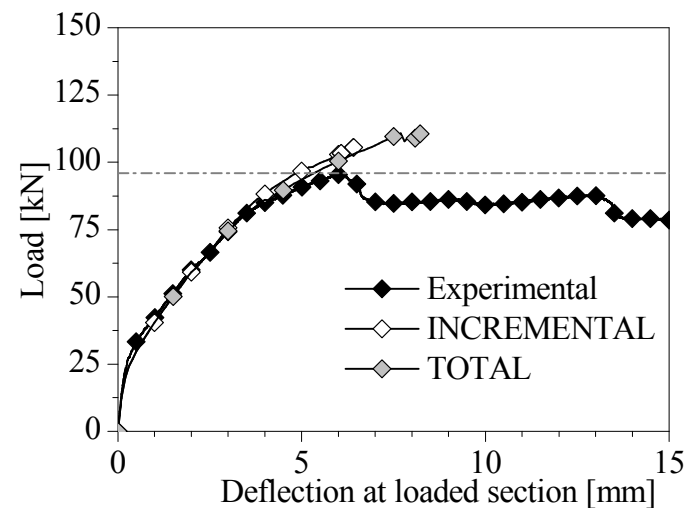

(c) - VL1

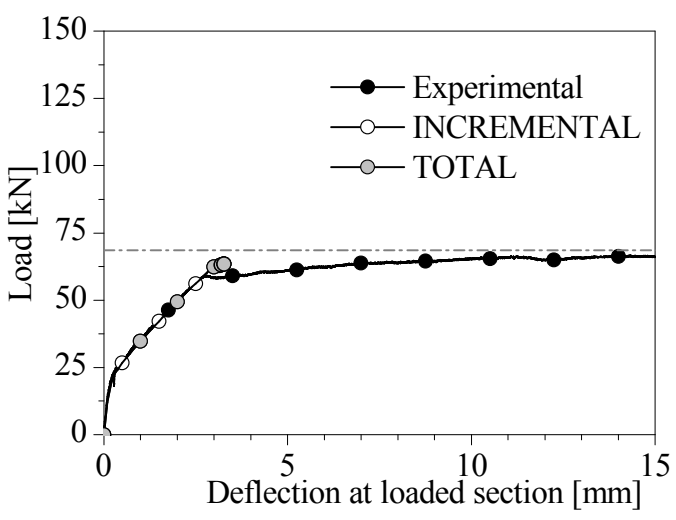

(b) - VE1

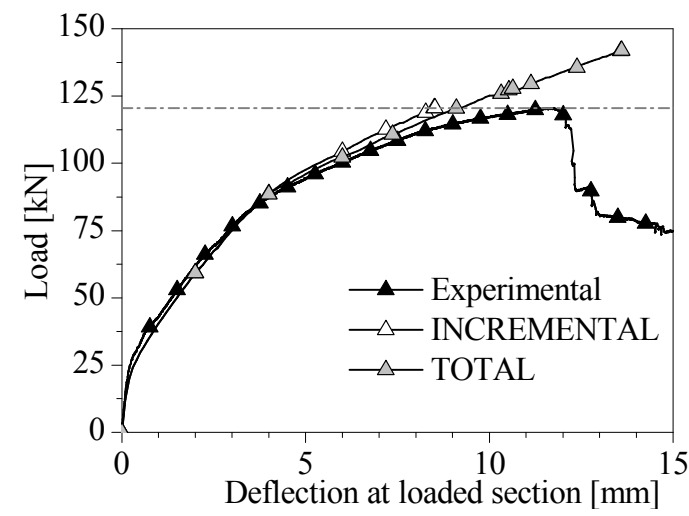

(d) - VLM1

Fig. 21. Load-deflection at the loaded section for the beams of Series 1. 


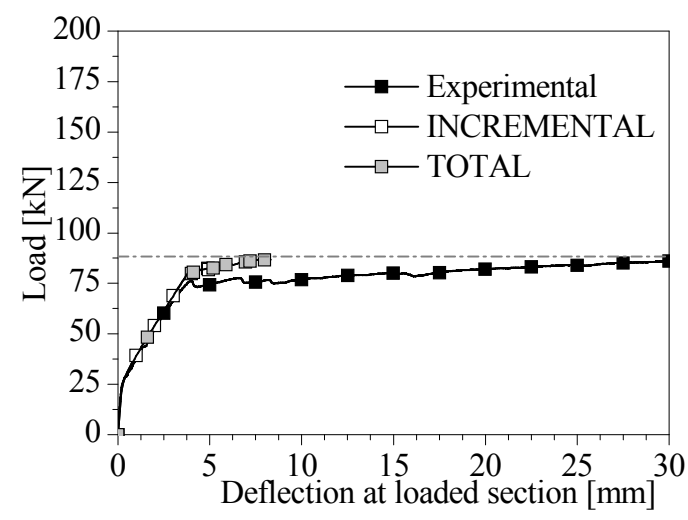

(a) - VR2

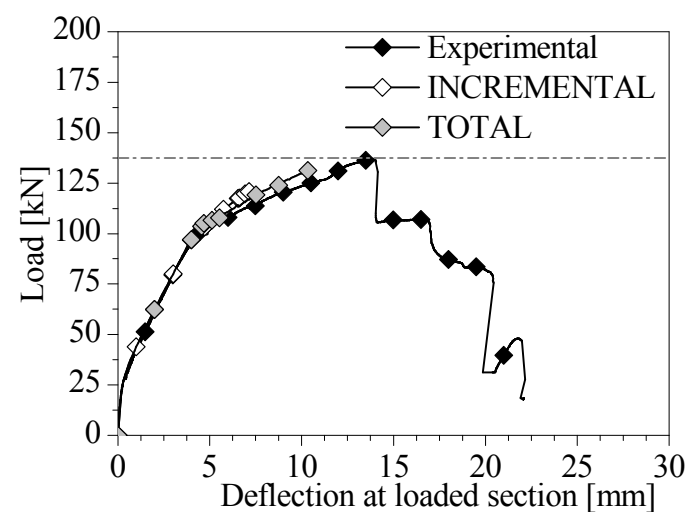

(c) - VL2

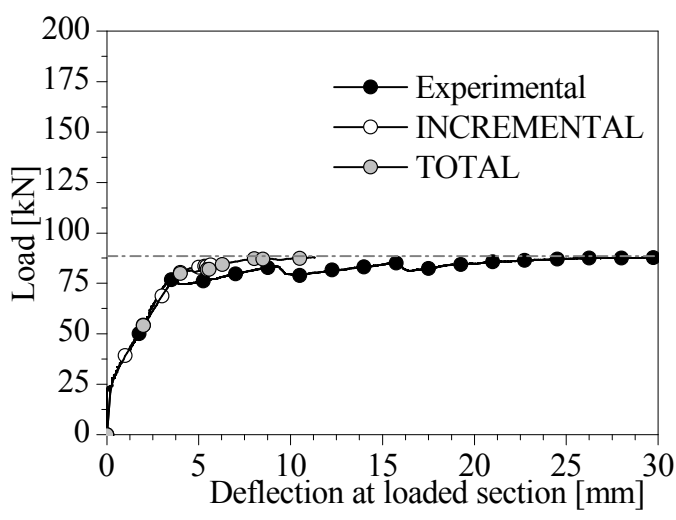

(b) - VE2

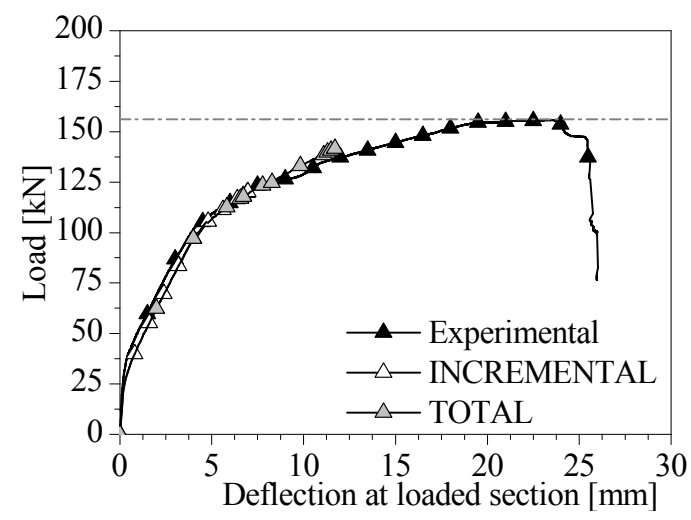

(d) - VLM2

Fig. 22. Load-deflection at the loaded section for the beams of Series 2. 


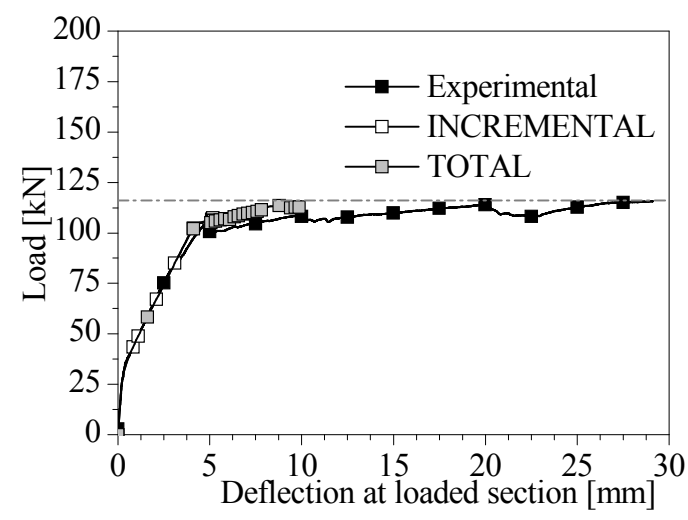

(a) - VR3

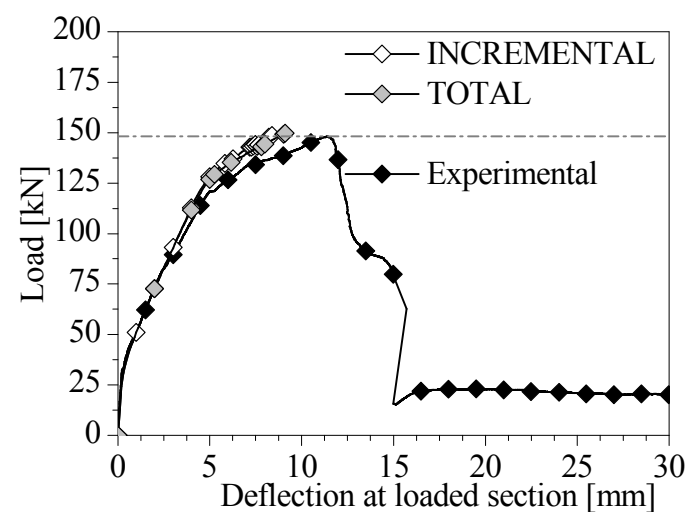

(c) - VL3

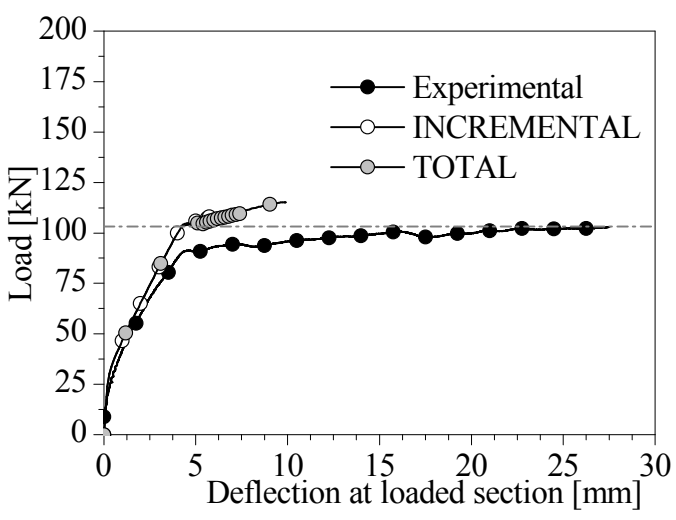

(b) - VE3

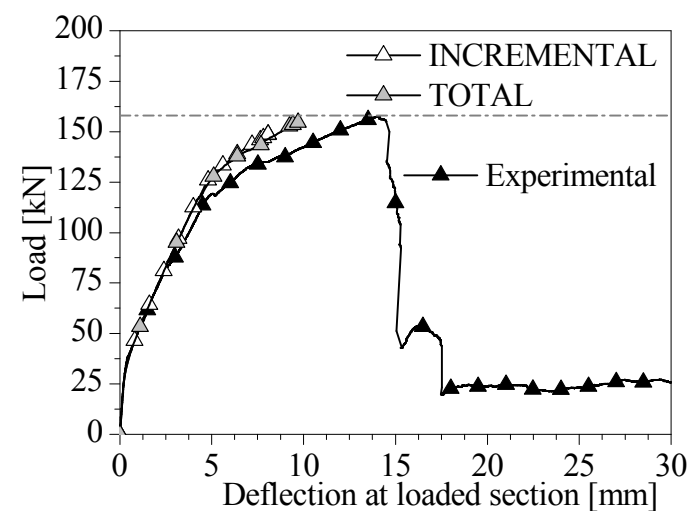

(d) - VLM3

Fig. 23. Load-deflection at the loaded section for the beams of Series 3. 
INCREMENTAL

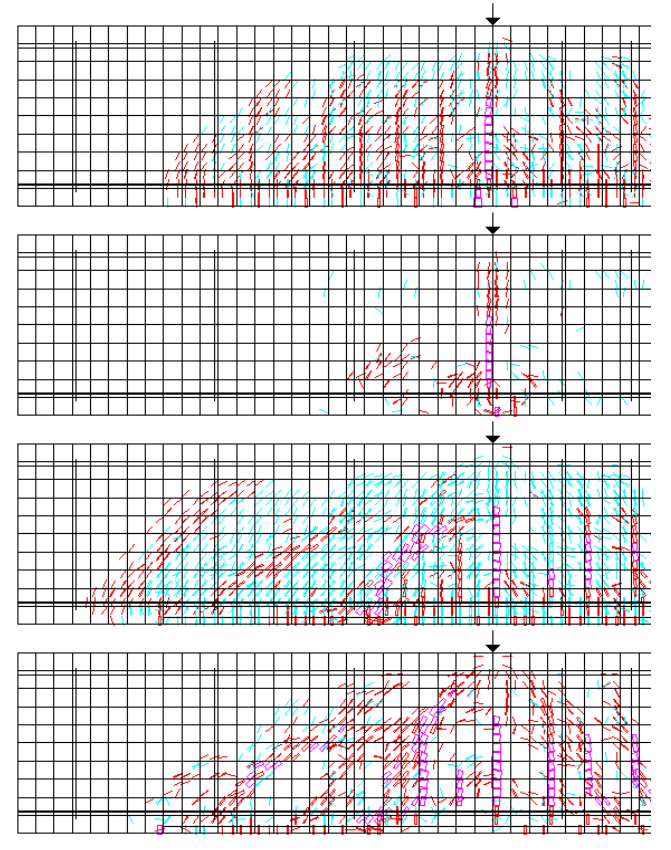

TOTAL

VR1

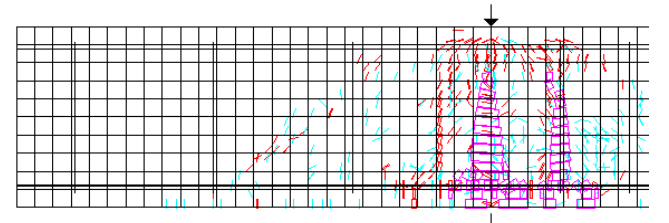

VE1

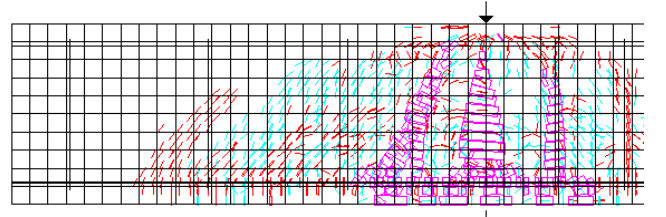

VL1

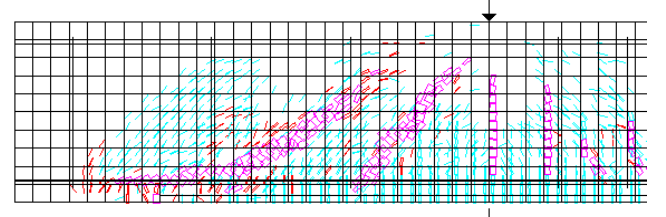

VLM1

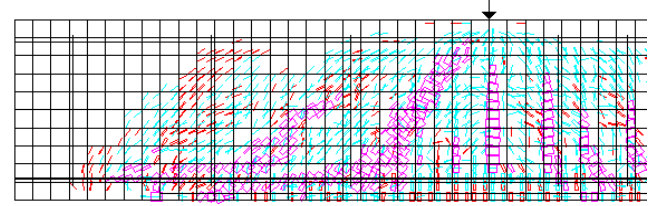

Fig. 24. Crack patterns of the beams of Series 1 (in pink colour: crack completely open $\left(\varepsilon_{n}^{c r} \geq \varepsilon_{n, u}^{c r}\right)$; in red colour: crack in the opening process; in cyan colour: crack in the reopening process). 
INCREMENTAL
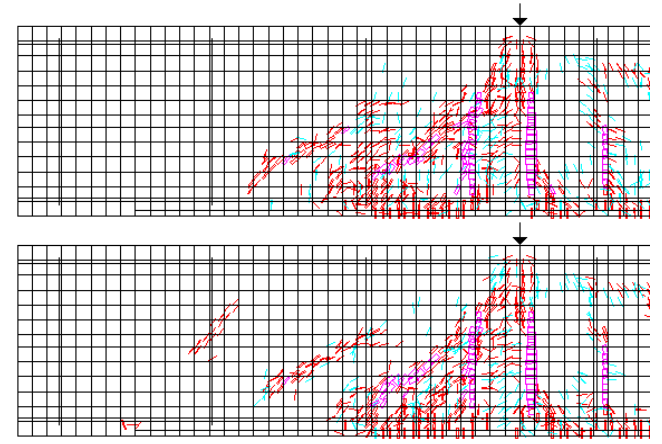

TOTAL

VL2

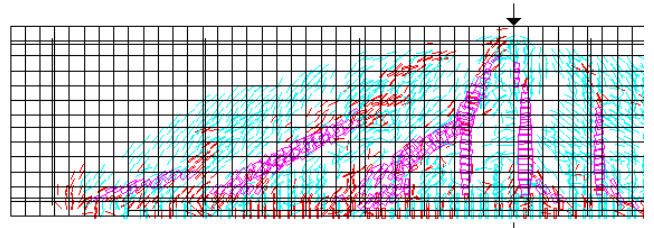

VLM2

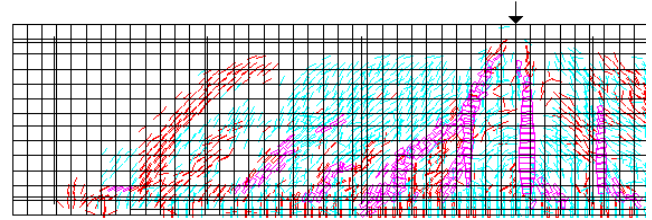

Fig. 25. Crack patterns of the beams of Series 2 (in pink colour: crack completely open $\left(\varepsilon_{n}^{c r} \geq \varepsilon_{n, u}^{c r}\right)$; in red colour: crack in the opening process; in cyan colour: crack in the reopening process). 
INCREMENTAL

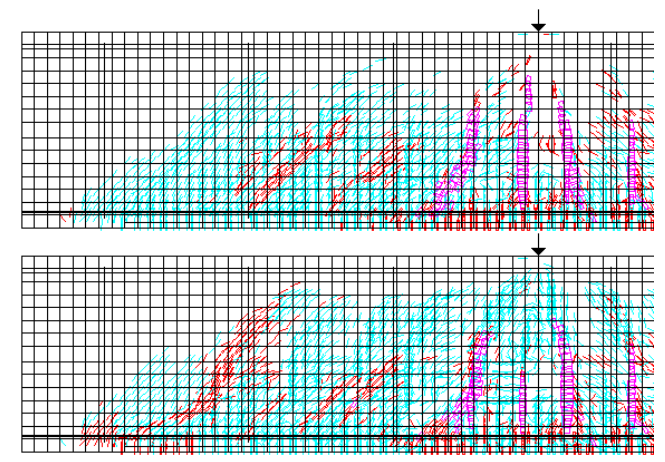

TOTAL

VL3

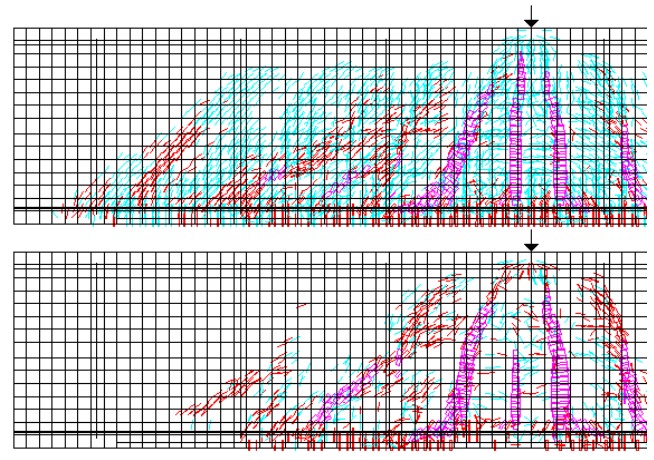

Fig. 26. Crack patterns of the beams of Series 3 (in pink colour: crack completely open $\left(\varepsilon_{n}^{c r} \geq \varepsilon_{n, u}^{c r}\right)$; in red colour: crack in the opening process; in cyan colour: crack in the reopening process). 


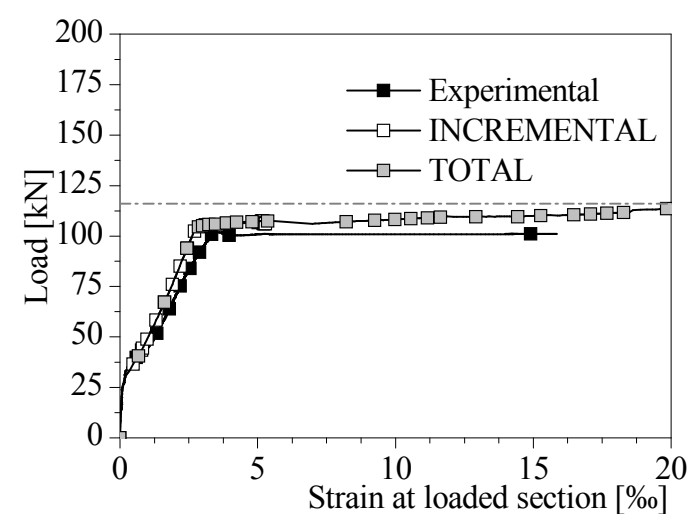

(a) - VR3

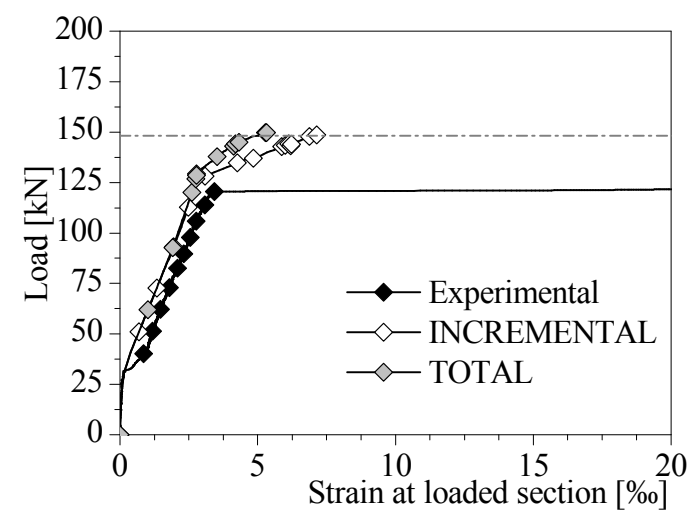

(c) - VL3

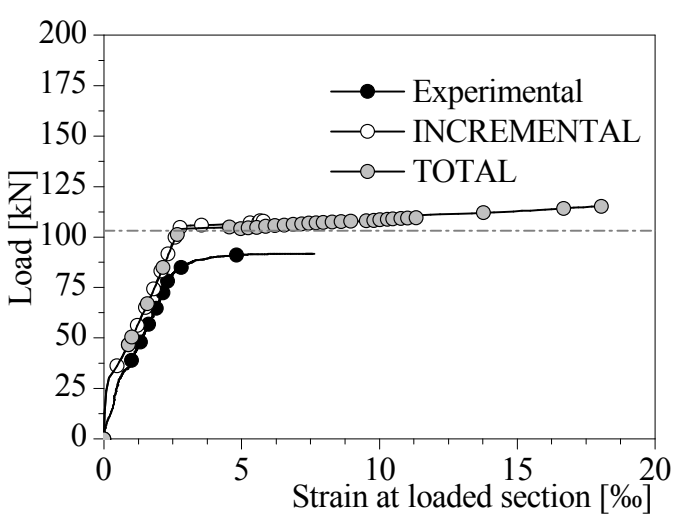

(b) - VE3

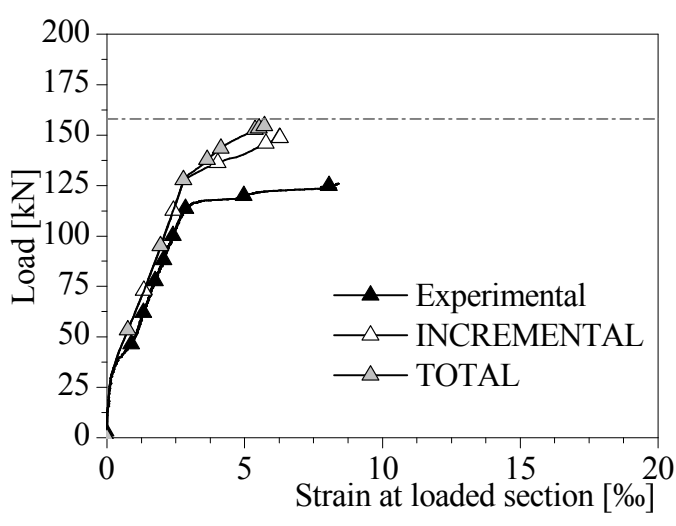

(d) - VLM3

Fig. 27. Relationship between the strains in the longitudinal steel bars $\left(S G_{S L}\right)$ and the applied load for the beams of Series 3 . 


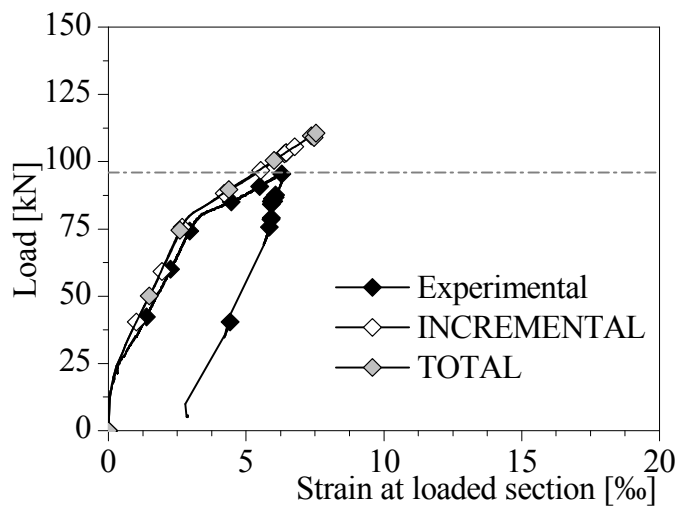

(a1) - VL1

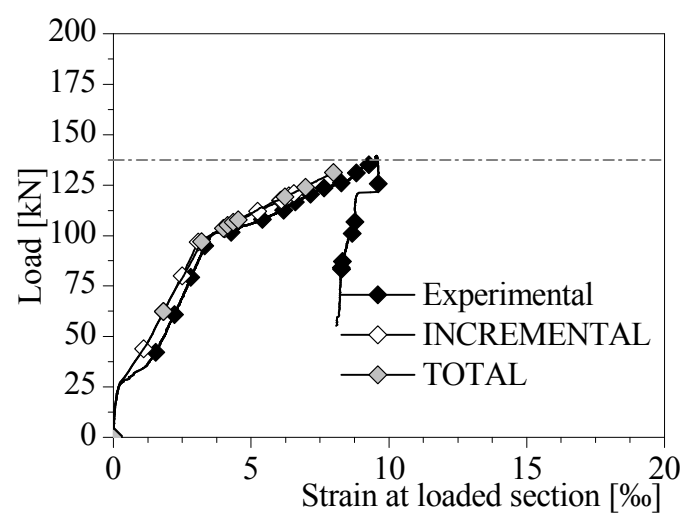

(a2) - VL2

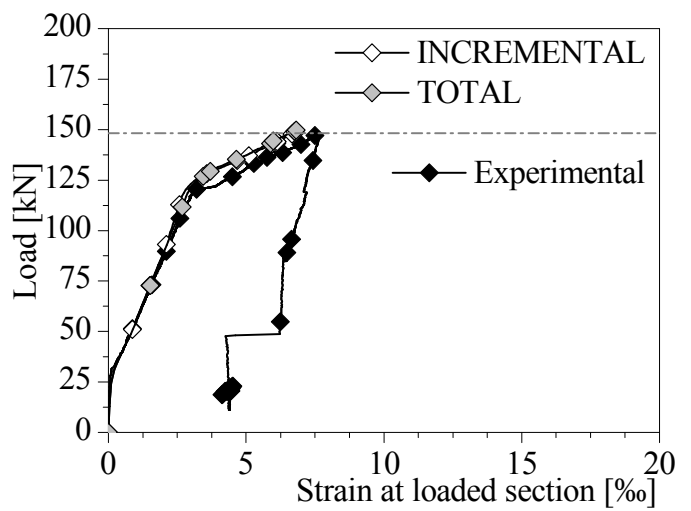

(a3) - VL3

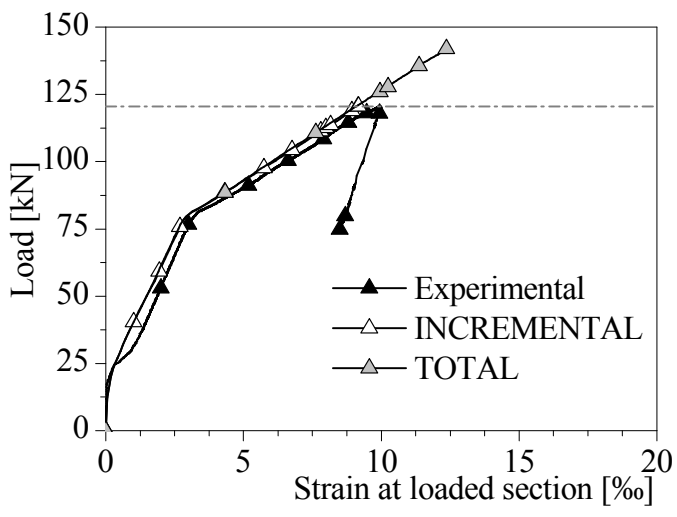

(b1) - VLM1

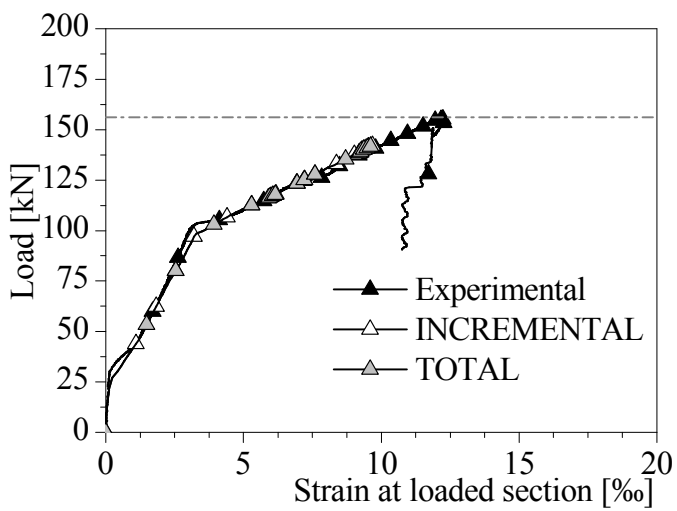

(b2) - VLM2

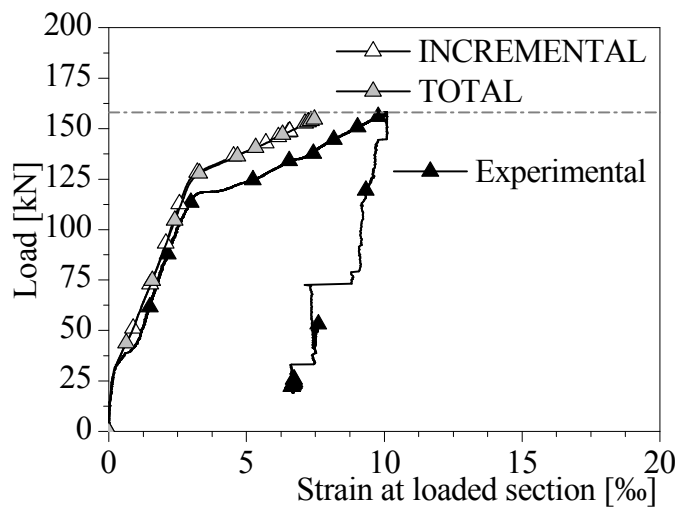

(b3) - VLM3

Fig. 28. Relationship between the strains in the NSM CFRP laminates $\left(S G_{C L 1,2}\right)$ and the applied load for the beams: (a1) VL1 and (b1) VLM1; (a2) VL2 and (b2) VLM2; (a3) VL3 and (b3) VLM3. 


\section{Tables}

Table 1. Dimensions of the beams of the three series.

Table 2. Steel properties.

Table 3. Properties of CFRP laminates and strips of sheets.

Table 4. Results from the beams of the tested series.

Table 5. Values of the parameters of the concrete constitutive model. 
Table 1. Dimensions of the beams of the three series.

\begin{tabular}{ccccccc}
\hline Series & $\begin{array}{c}L_{1} \\
{[\mathrm{~mm}]}\end{array}$ & $\begin{array}{c}L_{2} \\
{[\mathrm{~mm}]}\end{array}$ & $\begin{array}{c}b \\
{[\mathrm{~mm}]}\end{array}$ & $\begin{array}{c}h \\
{[\mathrm{~mm}]}\end{array}$ & $\begin{array}{c}A_{s}^{+\S} \\
{\left[\mathrm{mm}^{2}\right]}\end{array}$ & $\begin{array}{c}A_{s}^{-\S \S} \\
{\left[\mathrm{mm}^{2}\right]}\end{array}$ \\
\hline 1 & 550 & 950 & 200 & 250 & $2 \phi 10+1 \phi 6(185)$ & $2 \phi 10(157)$ \\
2 & 750 & 1150 & 200 & 320 & $2 \phi 10+1 \phi 10(236)$ & $2 \phi 10(157)$ \\
3 & 900 & 1300 & 200 & 380 & $2 \phi 12+1 \phi 8(276)$ & $2 \phi 12(226)$ \\
\hline
\end{tabular}

$\S$ Longitudinal steel bars at bottom surface (cross sectional area in $\mathrm{mm}$ )

$\S \S$ Longitudinal steel bars at top surface (cross sectional area in $\mathrm{mm}$ )

Table 2. Steel properties.

\begin{tabular}{ccccc}
\hline Property & $\phi 6$ & $\phi 8$ & $\phi 10$ & $\phi 12$ \\
\hline$f_{\text {sym }}(\mathrm{MPa})$ & 571 & 546 & 548 & 597 \\
$f_{\text {sum }}(\mathrm{MPa})$ & 662 & 653 & 648 & 738 \\
$E_{\text {sm }}(\mathrm{GPa})$ & 166 & 173 & 174 & 202 \\
$\varepsilon_{s y}(\%)$ & 3.1 & 2.9 & 3.0 & 2.8 \\
$\sigma_{s y}(\mathrm{MPa})$ & 515 & 504 & 514 & 569 \\
$\varepsilon_{\text {sh }}(\%)$ & 25 & 25 & 25 & 25 \\
$\sigma_{s h}(\mathrm{MPa})$ & 579 & 579 & 576 & 649 \\
$\varepsilon_{s h}(\%)$ & 50 & 50 & 50 & 50 \\
$\sigma_{s h}(\mathrm{MPa})$ & 643 & 643 & 637 & 729 \\
Third branch exponent & 1 & 1 & 1 & 1 \\
\hline
\end{tabular}

Table 3. Properties of CFRP laminates and strips of sheets.

\begin{tabular}{ccc}
\hline \multirow{2}{*}{ Property } & & \\
\cline { 2 - 3 } & CFK Laminate & C Sheet 240 \\
\hline$f_{f u}(\mathrm{MPa})$ & 2783 & 3257 \\
$E_{f}(\mathrm{GPa})$ & 157 & 237 \\
$\varepsilon_{f u}(\%)$ & 17.8 & 13.77 \\
$t_{f}(\mathrm{~mm})$ & 1.42 & 0.117 \\
\hline
\end{tabular}


Table 4. Results from the beams of the tested series.

\begin{tabular}{|c|c|c|c|c|c|c|c|c|c|c|c|}
\hline \multirow[t]{2}{*}{ Beam } & \multicolumn{3}{|c|}{$\begin{array}{l}\text { Age at testing beams } \\
\text { [days }]\end{array}$} & \multirow[t]{2}{*}{$\begin{array}{c}F_{s y} \\
{[\mathrm{kN}]}\end{array}$} & \multirow[t]{2}{*}{$\begin{array}{l}F_{\max } \\
{[\mathrm{kN}]}\end{array}$} & \multirow[t]{2}{*}{$\frac{F_{\max }}{F_{V R}}$} & \multirow[t]{2}{*}{$\frac{F_{\max }}{F_{V E}}$} & \multirow[t]{2}{*}{$\begin{array}{c}\varepsilon_{f L, F \max } \\
{[\% 0]}\end{array}$} & \multirow[t]{2}{*}{$\begin{array}{c}\varepsilon_{f L, \max } \\
{\left[\%{ }^{\circ}\right]}\end{array}$} & \multirow[t]{2}{*}{$\begin{array}{c}\varepsilon_{f V, F \max } \\
{[\% \circ]}\end{array}$} & \multirow[t]{2}{*}{$\begin{array}{c}\varepsilon_{f V, \max } \\
{[\% 0]}\end{array}$} \\
\hline & $\mathrm{RC}$ & NSM & EBR & & & & & & & & \\
\hline VR1 & 35 & - & - & 58 & 67 & 1.00 & 0.98 & - & - & - & - \\
\hline VE1 & 37 & - & - & 57 & 69 & 1.02 & 1.00 & - & - & - & - \\
\hline VL1 & 50 & 14 & - & 81 & 96 & 1.43 & 1.40 & 6.4 & 6.4 & - & - \\
\hline VLM1 & 67 & 31 & 9 & 79 & 121 & 1.80 & 1.76 & 10.0 & 10.0 & 6.2 & 7.5 \\
\hline VR2 & 38 & - & - & 70 & 88 & 1.00 & 1.00 & - & - & - & - \\
\hline VE2 & 37 & - & - & - & 89 & 1.00 & 1.00 & - & - & - & - \\
\hline VL2 & 51 & 9 & - & 87 & 137 & 1.55 & 1.55 & 9.6 & 9.6 & - & - \\
\hline VLM2 & 66 & 24 & 8 & - & 156 & 1.77 & 1.76 & 12.3 & 12.3 & 3.9 & 4.0 \\
\hline VR3 & 53 & - & - & 90 & 116 & 1.00 & 1.12 & - & - & - & - \\
\hline VE3 & 53 & - & - & 85 & 103 & 0.89 & 1.00 & - & - & - & - \\
\hline VL3 & 58 & 8 & - & 107 & 148 & 1.28 & 1.44 & 7.6 & 7.7 & - & - \\
\hline VLM3 & 65 & 14 & 7 & 112 & 158 & 1.36 & 1.53 & 10.0 & 10.1 & 5.0 & 9.5 \\
\hline
\end{tabular}

Table 5. Values of the parameters of the concrete constitutive model.

\begin{tabular}{cc}
\hline Property & Value \\
\hline$v_{c}$ & 0.2 \\
$E_{c}^{\S}[\mathrm{GPa}]$ & 28.9 \\
$f_{c m}{ }^{\S}[\mathrm{MPa}]$ & 31.1 \\
$f_{c t}[\mathrm{MPa}]$ & 1.5 \\
$\alpha_{1}$ & 0.50 \\
$\xi_{1}$ & 0.10 \\
$\alpha_{2}$ & 0.20 \\
$\xi_{2}$ & 0.30 \\
$G_{f}^{I}[\mathrm{~N} / \mathrm{mm}]$ & 0.0665 \\
$p_{1}{ }^{\S \S}$ & 3 \\
$l_{b}$ & 1 \\
$N_{c r, \max }$ & $\sqrt{A_{I P}}$ \\
$\theta_{t h}$ & 2 \\
\hline
\end{tabular}

\footnotetext{
$\S$ Experimentally determined

$\S \S$ Parameter defining the $G_{f}^{I}$ available to the new crack [18]
} 